Portland State University

PDXScholar

Spring 6-5-2019

\title{
Development and Validation of the Workplace Mental IIIness Stigma Scale (W-MISS)
}

Nicholas Anthony Smith

Portland State University

Follow this and additional works at: https://pdxscholar.library.pdx.edu/open_access_etds

Part of the Mental and Social Health Commons, and the Psychology Commons Let us know how access to this document benefits you.

\section{Recommended Citation}

Smith, Nicholas Anthony, "Development and Validation of the Workplace Mental IIIness Stigma Scale (WMISS)" (2019). Dissertations and Theses. Paper 5011.

https://doi.org/10.15760/etd.6887

This Dissertation is brought to you for free and open access. It has been accepted for inclusion in Dissertations and Theses by an authorized administrator of PDXScholar. Please contact us if we can make this document more accessible: pdxscholar@pdx.edu. 
Development and Validation of the

Workplace Mental Illness Stigma Scale (W-MISS)

by

Nicholas Anthony Smith

A dissertation submitted in partial fulfillment of the requirements for the degree of

Doctor of Philosophy

in

Applied Psychology

Dissertation Committee:

Jennifer Dimoff, Chair

Leslie Hammer

Donald Truxillo

Wayne Wakeland

Portland State University

2019 
(C) 2019 Nicholas Anthony Smith 


\begin{abstract}
Although 1 in 5 Americans will experience a mental illness at some point, each year people with mental illnesses continue to face high levels of stigmatization and discrimination at work. Recognizing this, many organizational researchers and practitioners have sought to improve workplaces for employees with mental illness through a variety of organizational interventions. Unfortunately, few interventions are thoroughly evaluated. One barrier to evaluating such interventions is the lack of a theoretically meaningful measure of workplace mental illness stigma. In this dissertation, I proposed to develop and evaluate such a measure (the W-MISS) based on Jones, Farina, Hastorf, Markus, Miller, and Scott's (1984) six-dimension stigma framework (i.e., concealability, course, disruptiveness, aesthetics, origin, and peril). To do so, I used Hinkin's (1998) approach: Phase 1) item generation was completed by 8 subject matter experts; Phase 2) content validity evidence was provided by 47 adults with management experience and 7 subject matter experts; Phase 3) exploratory factor analysis was conducted based on responses from 300 adults with management experience; Phase 4) confirmatory factor analysis was conducted based on responses from 200 adults with management experience; Phase 5) convergent and discriminant validity evidence was provided by 101 adults with management experience; and Phase 6) predictive validity evidence with regard to hiring discrimination was provided by 365 adults with management experience. Overall, the results supported the hypothesized factorial structure, convergent and discriminant validity, and predictive utility of the W-MISS. Findings provide empirical support for Jones et al.'s (1984) theoretical stigma framework
\end{abstract}


in a workplace context for mental illness and represent the first comprehensive measure development drawing on these dimensions for any stigmatized identity in a workplace context. Further, results demonstrate the potential for scholarly and practical utility of such a measure. 


\section{Acknowledgements}

I wish to acknowledge a number of people for their contributions. I first sincerely thank my advisor, Jennifer Dimoff, for her expertise and guidance. Throughout my training, I have come to deeply understand and appreciate the importance of the scientistpractitioner model for making change and conducting actionable research that matters. I can confidently state that I have grown as a scholar and a professional due to working with such an excellent advisor.

I also thank the other members of my dissertation committee. First, Leslie Hammer, who is a fierce advocate and continues to provide guidance. Second, Donald Truxillo, who is a wonderful mentor and teacher, and continues to support my research and professional development. Third, Wayne Wakeland, who has enthusiastically provided feedback throughout the development and execution of my dissertation. Each contributed to the strength of this dissertation in innumerable ways.

I additionally wish to thank the faculty members and staff at Portland State for all of their guidance and instruction throughout my graduate training. Further, I thank my graduate student colleagues and peers who provided support throughout my time in Portland. 


\section{Table of Contents}

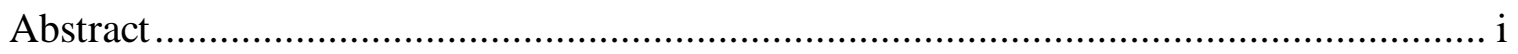

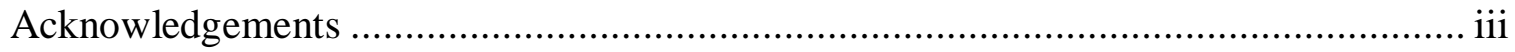

Table of Contents ....................................................................................... iv

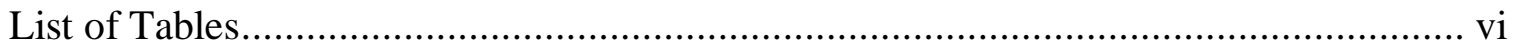

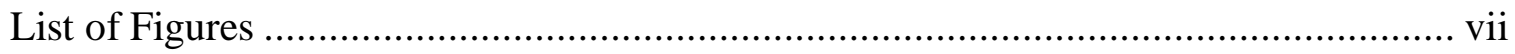

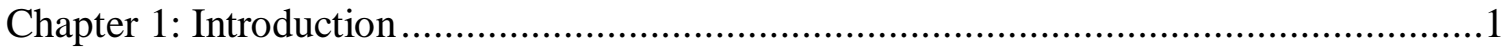

Mental Illness Stigma and the Workplace ..........................................................4

Chapter 2: Literature Review .......................................................................

Theoretical Framework for Stigma ........................................................ 11

Observer Stigma Perceptions and Behavioral Outcomes ................................... 17

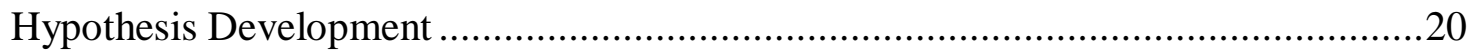

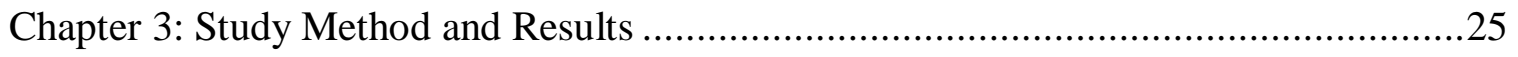

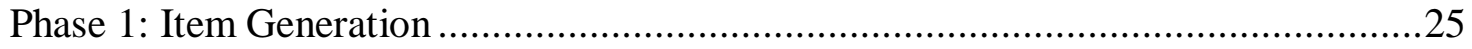

Phase 2: Content Validation/Item Reduction .....................................................29

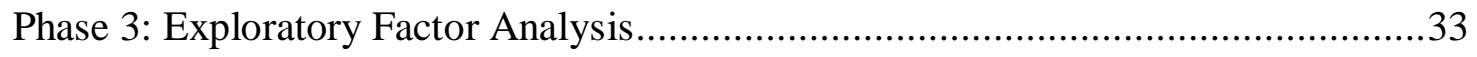

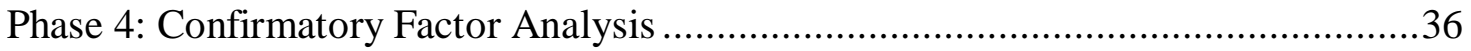

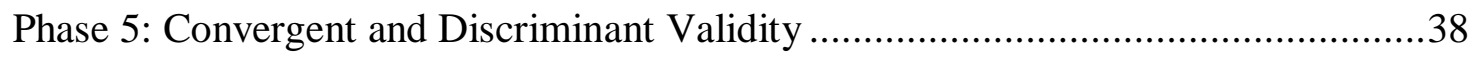

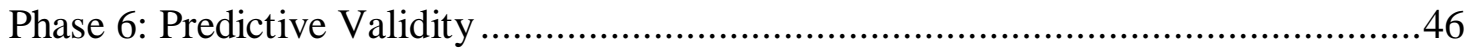

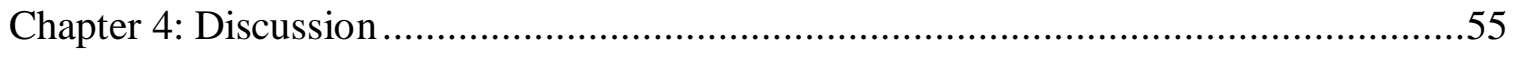

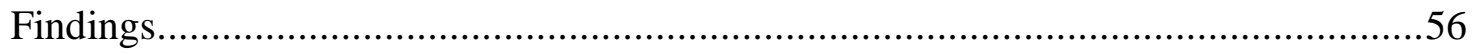

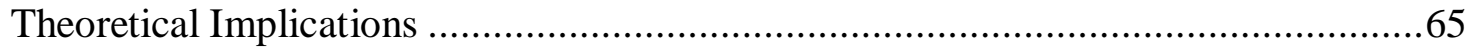




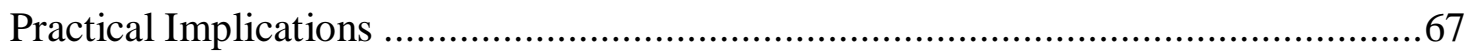

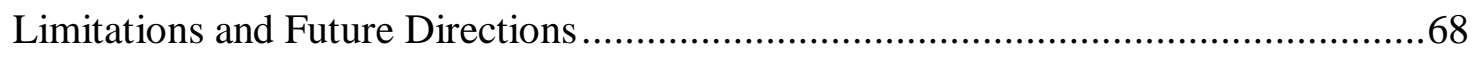

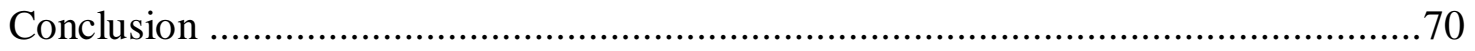

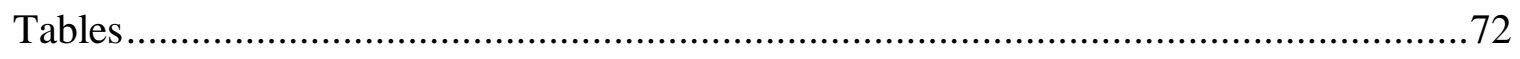

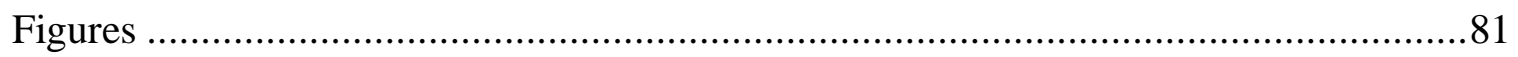

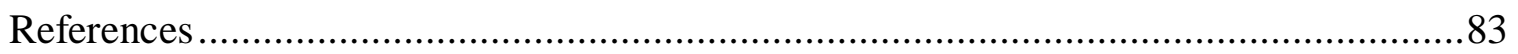

Appendix A: SME Instruction Sheet ........................................................ 104

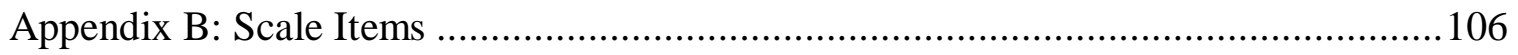

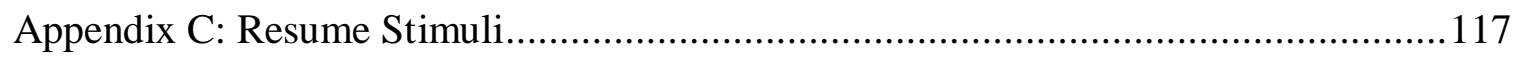




\section{List of Tables}

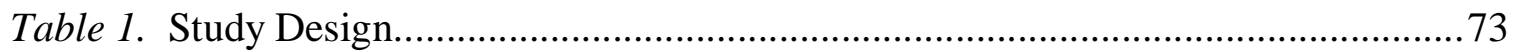

Table 2. Summary of Exploratory Factor Analysis Results.............................................74

Table 3. Confirmatory Factor Analysis Model Comparisons...........................................75

Table 4. Summary of Convergent / Discriminant Validity Results...................................77

Table 5. Summary of Incremental Validity Results.......................................................78

Table 6. Examination of mental illness types on outcomes.............................................79

Table 7. RWA analysis for W-MISS across mental illness types.....................................80 


\section{List of Figures}

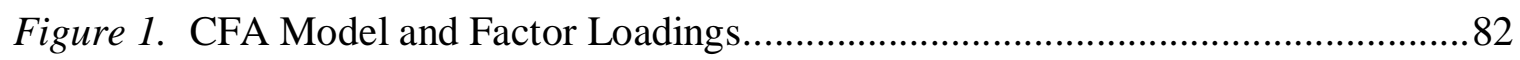




\section{Chapter 1: Introduction}

Mental illness is nothing to be ashamed of, but stigma and bias shame us all. -Bill Clinton

In 1981, the New York Times released an article in which they detailed how individuals with mental illnesses (i.e., a wide range of mental health problems characterized by significant distress and impaired functioning over an extended period of time) were unable to seek treatment because they were afraid to provide the necessary insurance documentation to their employer - a requirement for healthcare claims at the time (Sobel, 1981). Although 35 years have passed and the legal and social landscape has changed, mental illness status continues to be an extremely stigmatized identity (Corrigan, 2005). This ongoing stigmatization continues despite how common this identity is in the US and across the world, with depression and anxiety constituting the most common of mental illnesses in the working population (MHCC, 2011). In fact, one in five individuals will experience a mental illness every year (National Institute of Mental Health, n.d.), and approximately $46 \%$ of individuals will meet the criteria for a particular mental illness at some point in their lifetime (Kessler et al., 2005). Further, even though mental illness has been a protected class (i.e., disability) since the Americans with Disability Act, people with mental illnesses continue to be particularly stigmatized in the work domain (see Follmer \& Jones, 2018).

Although the target of stigma has the agency to draw upon their identity in order to change the environment around them (e.g., identity management, identity deployment; Creed \& Scully, 2000; Ragins, 2008), environmental factors, such as societal and cultural norms, can also influence the targeted individual and how targets are viewed. In media, 
individuals with mental illness are often portrayed as unstable and dangerous, feeding into stereotypic, prejudicial, and discriminatory responses toward such individuals (Sieff, 2003). Specific industries, such as construction, may be considered less accepting of particular identities based on perceptions of the prototypical worker in that industry (e.g., Perry \& Finkelstein, 1999). At the organizational level, certain organizations may have cultures and climates that are particularly accepting of stigmatized identities, which may be based on implicit and explicit values and protocols that exist within the organization (see Kossek \& Zonia, 1993). For instance, organizations such as Starbucks and Walt Disney World Parks and Resorts espouse strong values with regard to diversity and inclusion and enact inclusive policies and procedures (e.g., Walt Disney World provided same-sex domestic partner benefits long before required by law; Starbucks recently announced that they would close all of their stores to provide racial-bias training to almost 175,000 U.S. partners [employees]; Starbucks, 2018). Even workgroups may be viewed as more or less accepting depending upon top-down (leaders) or bottom-up (grassroots) processes that "set the stage" for what is perceived as important and acceptable in the workgroup (see Shore et al., 2011). Thus, it may be argued that employees with stigmatized identities are active members of a system in which they can impact others around them, their organizations, and their immediate workplaces and in turn, may be acted upon by these same forces.

There are no reliable, validated measures of workplace mental illness stigma in the Industrial/Organizational Psychology literature. This dearth of measurement makes it difficult for researchers and practitioners to a) understand the workplace-specific stigma 
surrounding mental illness, and b) influence coworker and leader behaviors in such a way that leads to less stigma and less discrimination. Further, although workplace interventions have been developed to change mental illness stigma perceptions (Dimoff \& Kelloway, 2019; Oakie, Smith, Dimoff, \& Kelloway, 2018), the lack of validated workplace mental illness scales limits the ability to evaluate the effectiveness of these interventions. The purpose of this dissertation was twofold: a) to develop and validate a multidimensional measure of workplace mental illness stigma that can be used to evaluate one source of environmental influence - manager perceptions of workers with a mental illness; and b) to better understand how these perceptions are related to specific observers' behavior (i.e., hiring decisions) toward people with mental illness. Thus, the ultimate goal of this dissertation was to begin providing a stronger, more theoreticallydriven foundation for the literature on mental illness stigma in the workplace.

The Workplace Mental Illness Stigma Scale (W-MISS) that I developed and gathered validation evidence for as part of this dissertation captured Jones et al.'s (1984) six-dimension stigma framework (i.e., concealability, course, disruptiveness, aesthetics, origin, and peril). In addition to this theoretical framework, I also used a social cognitive perspective to examine the stigma perceptions toward individuals with four types of mental illness (i.e., depression, anxiety, substance use disorder, and schizophrenia). These four mental illnesses were chosen because they are among the most prevalent mental illnesses within the general working population (i.e., depression and anxiety) or are commonly referenced in popular culture (i.e., schizophrenia, substance use disorder). 
To develop and validate the W-MISS, I used Hinkin's (1998) traditional approach: 1) item generation, 2) content validation/item reduction, 3) exploratory factor analysis, 4) confirmatory factor analysis, 5) convergent/discriminant validity evaluation, and 6) predictive validity evaluation. In total, this work required 7 samples, in which 2903 individual were recruited to result in a final total sample of 1030 individuals. The two outcomes of this dissertation are as follows: 1) the first theory-driven measurement tool of workplace mental illness stigma with validation evidence, and 2) a better understanding of how observer stigma leads to target discrimination (i.e., hiring decision).

\section{Mental Illness Stigma and the Workplace}

Given the prevalence of mental illnesses within the working population, and the stigma surrounding mental illness, it is important to consider mental illness from a workplace perspective. First, mental illness is associated with negative work and life outcomes. Those with a mental illness have a higher likelihood of mortality compared to the general population (Walker, McGee, \& Druss, 2015). Additionally, serious mental illness is associated with a high economic cost - nearly $\$ 318$ billion between healthcare expenditures, loss of earnings, and disability benefits paid in the United States alone (Insel, 2008). Second, mental illness stigma may exacerbate such negative outcomes. For example, in a study conducted across 25 countries, national-level mental illness stigma was found to predict suicide rates per country (Schomerus et al., 2015). Indeed, mental illness stigma has been linked to impeding individuals with mental illness seeking care (Corrigan, Druss, \& Perlick, 2014). Third, relatively little is known in 
organizational science about the impacts of mental illness and mental illness stigma in workplace contexts, and much of the work that has been conducted has been largely atheoretical (see Follmer \& Jones, 2018 for a cross-disciplinary review). Fourth, when mental illness and mental illness stigma have been considered, researchers typically have not examined specific types of mental illness; when they have, usually only one single mental illness (e.g., depression) is examined without reference to how it may differ from others in terms of stigma perceptions and behavioral outcomes. Finally, no measure of mental illness stigma has undergone a rigorous validation in the workplace context. Effective measurement is imperative to understanding the impact of workplace mental illness stigma, and to developing theoretically and practically relevant interventions.

In order to fill these gaps in the literature, I planned and conducted a measure development study, resulting in a multidimensional workplace mental illness stigma scale, the W-MISS. To theoretically support the rationale for this scale, I first review organizational literature related to mental illness stigmatization. Second, I discuss mental illness in the context of social identity. Third, I discuss the theoretical conceptualization of stigma (Goffman, 1963; Jones et al., 1984), along with its importance in terms of stigmatization - particularly with regard to stigma on behavioral outcomes (discrimination). Based on this review, I then assert a series of hypotheses, present findings from the development of the W-MISS, and discuss theoretical and practical implications, along with limitations and avenues for future research.

As mentioned above, the measure development was conducted in multiple phases, using Hinkin's (1998) approach. Phase 1 included item generation using a deductive 
scale approach based on the six stigma dimensions proposed by Jones et al. (1984). In this phase, subject matter experts were provided with definitions of each of the stigma dimensions, and wrote items in reference to mental illness status in a workplace context. These items were screened by a professor of applied psychology who is an expert in the area of workplace mental health and me. Phase 2 included content validation and item reduction. In the content validation portion of Phase 2, raters from Amazon's MTurk were provided with the definitions of each stigma dimension and were asked to sort the items into their respective dimensions. In the item reduction portion of Phase 2, subject matter experts rated the remaining items from the content validation portion of Phase 2 for relevancy and clarity. In Phase 3, a sample of participants from MTurk provided responses to the items of the W-MISS, which were then used to conduct a series of exploratory factor analyses to further refine the item pool for each dimension. In Phase 4, a separate sample of participants from MTurk responded to the remaining items of the W-MISS. These responses were then used to conduct confirmatory factor analyses to confirm the dimensionality of the W-MISS. In Phase 5, the convergent and discriminant validity of the W-MISS was assessed with a sample from MTurk in comparison to three theoretically related measures (e.g., general stigma toward mental illness) and three theoretically disparate measures (e.g., self-esteem). Finally, in Phase 6, predictive validity of the W-MISS was assessed with a sample from MTurk by asking participants to rate the perceived hireability of individuals with a mental illness along with their responses to the W-MISS and a general measure of mental illness stigma. I then 
examined the incremental validity of the W-MISS in comparison to a general measure of mental illness stigma (see Table 1 for a depiction of these phases).

This work contributes to the field by examining workplace mental illness stigma from a highly theoretical basis in order to provide a rigorous and practical measurement tool. Thus, this work could serve as a springboard for future theoretical and intervention research in the workplace mental illness space. Currently, there are no published workplace specific measures of mental illness stigma. Ultimately, with this study, I seek to introduce the first workplace mental illness stigma measure with accompanying validation evidence that can be used for purposes within academia and practice. 


\section{Chapter 2: Literature Review}

Mental illness refers to a diagnosable psychological disorder "characterized by dysregulation of mood, thought, and/or behavior" (Center for Disease Control and Prevention, 2016), of which nearly 300 are classified in the American Psychiatric Association's current (fifth) edition of the Diagnostic and Statistical Manual of Mental

Disorders (DSM-V; American Psychiatric Association, 2013). Mental illnesses differ in a number of important ways, such as age of onset, chronicity, and severity (both within and across illnesses; American Psychiatric Association, 2013). As such, mental illnesses may be more or less noticeable to others and may create higher or lower levels of interpersonal difficulties. However, early and ongoing treatment can be effective in reducing the severity and disruptiveness of symptoms (Briner, Amati, \& Lardner, 2003; de Lange, Taris, Kompier, Houtman, \& Bongers, 2004; Nieuwenhuijsen, Verbeek, de Boer, Blonk, \& van Dijk, 2004). Even though many organizations have taken considerable steps in implementing resources that can serve to enhance mental health and reduce the symptoms associated with mental illnesses, resource utilization rates remain low (Linnan et al., 2008).

Stigma is considered one of the primary reasons for low utilization of mental health resources (Corrigan et al., 2014). Prior researchers have considered specific factors that may explain this low utilization (e.g., the resource utilization model; Dimoff \& Kelloway, 2016). However, little workplace research has conceptualized mental illness and mental illness stigma by using an identity-based perspective. By examining mental illness from an identity perspective, it may be possible to better understand the 
stigma surrounding mental illness and specific mental illnesses. From a basic perspective, in order for individuals to seek or receive resources or treatment for their mental illness, they must first recognize and admit that their mental health status has become compromised. This recognition is dependent upon some form of identification between the individual and their mental health.

Individuals with mental illness can conceptualize their mental illness as part of their social identity. Tajfel and Turner (1986, p. 16) defined social identity as "those aspects of an individual's self-image that derive from the social categories to which he perceives himself as belonging." To be a member of these social groups, it is not required that an individual interacts with or shares goals with other members of the group. Rather, the major criterion is that these individuals "define themselves and are defined by others as members of [the] group" (Tajfel \& Turner, 1986, p. 15). Conceptualizing mental illness status as a social identity is not only appropriate but is also advantageous for several reasons. Follmer and Jones (2018, p. 329) succinctly argue the following:

Having a mental illness creates a unique perspective through which individuals interact with the workplace, and such a perspective is markedly different from that of individuals without mental illness. Furthermore, association with this identity can affect how others treat employees with mental illness. Importantly, not all employees with mental illness will experience the workplace in the same way. Instead, these experiences will vary across disorders and are shaped by the manifestation of symptoms as well as others' perceptions of the individual or mental illness.

Indeed, when one considers mental illness status as a social identity, then it is also possible to shift the narrative around how organizational leaders, managers, coworkers, and individuals with a mental illness status consider mental illness. For example, Onken 
and Slaten (2000) presented findings from a grounded theory study demonstrating that individuals with a severe mental illness can transition from experiencing shame to experiencing pride when they undergo a process of positive identity formation surrounding their mental illness status. When their mental illness status becomes integrated into their larger identity, they experienced more positive workplace and interpersonal interactions (Onken \& Slaten, 2000). Further, when conceptualizing mental illness status as a social identity, it is possible to draw upon the identity management literature, which suggests that disclosure may lead to positive outcomes by reducing the utilization of cognitive resources required to conceal one's stigmatized identity or by claiming (rather than downplaying) one's stigmatized identity (see Lyons et al., 2018; Nittrouer, Trump, O’Brien, \& Hebl, 2014). Treating "mental illness" as an affliction that should be concealed, or should go undiscussed, undisclosed, or unacknowledged may lead to low levels of identification. In turn, the stigma surrounding mental illness status, especially within workplace contexts, may be exacerbated and perpetuated.

Furthermore, to gain access to resources and appropriate types of treatments, which is related to a host of positive outcomes (e.g., symptom reduction), one must disclose their mental illness status, or at the very least, admit their mental illness status to oneself (Dimoff \& Kelloway, 2016). It is possible that the shame and stigma associated with mental illness might preclude individuals from utilizing such resources (Dimoff \& Kelloway, 2019). Additionally, it is possible to consider that mental illness status may operate similarly as other related stigmatized social identities. For example, another disability that is also a social identity which is stigmatized, mostly invisible, allows for 
the possibility of "recovery", and may involve "relapses", is cancer status/survivorship, which has been explored by organizational researchers (Crom et al., 2018; Martinez \& Hebl, 2016; Martinez, White, Shapiro, \& Hebl, 2016; Robinson, Kocum, Loughlin, Bryson, \& Dimoff, 2015). Overall, the findings from these studies suggest that those who have a history of or are currently diagnosed with cancer wish to have a sense of control about the disclosure of their membership in this social identity in workplace contexts (although extent of disclosure is related to generally positive workplace outcomes; Martinez \& Hebl, 2016; Robinson et al., 2015). However, cancer survivors are more negatively evaluated than their peers and are often met with interpersonal and formal discrimination, which is associated with negative job outcomes (Crom et al., 2018; Martinez et al., 2016). Those with a mental illness status may also experience similar outcomes.

\section{Theoretical Framework for Stigma}

Stigma was defined by Goffman (1963, p. 3) as some deeply discrediting attribute that reduces individuals "in our minds from a whole and usual person to a tainted, discounted one." Stigma theory suggests that attributes of a target have specific meanings in social contexts (Goffman, 1963). Additionally, these stigmatizing attributes are related to negative stereotypes (Jones et al., 1984), which result in negative behavioral outcomes toward individuals who either possess, or who are believed to possess, the particular stigmatizing attribute (Major \& O’Brien, 2005). Further, these stigmas are not necessarily perceived in the same manner across observers, thus the observers' 
perceptions of these attributes are particularly important to consider when attempting to predict cognitive, attitudinal, and behavioral outcomes.

One reason that these perceptions may differ across person and context is that they are influenced by past encounters with the target group (either in person or in popular culture), thus changing how individuals respond to such attributes (Jones et al., 1984). For example, sexual orientation, gender identity, and higher weight are perceived by some as attributes that are controllable, and by others as attributes that are not controllable. Indeed, Jones et al. (1984) discuss the process of person perception in the following manner: an observer has certain perceptions and attributions regarding initial cues, which then form expectancies about the target. In an interaction with the target, additional stimulus cues are said to be attended to (such as appearance, context, and behavior), which thus result in potentially changed perceptions and attributions. These stigmatizing attributes have also been theorized to fall into six important dimensions, including concealability, course, disruptiveness, aesthetics, origin, and peril (Jones et al., 1984).

Concealability refers to the extent to which the stigma is invisible or apparent to observers (Jones et al., 1984). For example, the loss of a limb is a highly visible disability, whereas mental illness is potentially concealable. Although researchers have demonstrated that stigmas that are readily apparent are more likely to experience negative reactions from observers (Gouvier, Steiner, Jackson, Schlater, \& Rain, 1991; Kleck, 1968), the concealability of a stigma may also be related to negative workplace outcomes. For example, those with a concealable stigmatized identity must make 
decisions regarding whether or not to disclose such an identity. With regard to disclosure, the individual must decide to whom to disclose, when to disclose, in what contexts to disclose, and how to disclose (see Clair, Beatty, \& Maclean, 2005; Ragins, 2008). Depending on how these decisions are made, observers may view the individual with the stigmatized identity as deceitful or untrustworthy (Jones et al., 1984). With regard to mental illness, even though symptoms may decrease, observers may still fear such individuals, as these symptoms are often invisible in nature, resulting in difficulties with regard to predicting behavior (Jones et al., 1984). Additionally, the often-invisible nature of mental illness may cause observers to question the legitimacy of the mental illness and the need for associated workplace accommodations (Krupa, Kirsh, Cockburn, \& Gewurtz, 2009).

Course refers to the extent to which the stigma may or may not change over time and the perceived ultimate outcome of the stigma (Jones et al., 1984). For example, HIV, although currently incurable, may be managed over the course of the lifetime with adherence to combination antiretroviral therapy (Teeraananchai, Kerr, Amin, Ruxrungtham, \& Law, 2016). Regarding individuals with disabilities, Stone and Colella (1996) argue that the more chronic, progressive, or incurable that the disability is perceived to be, the more negative the workplace outcomes. For relatively concealable stigmas such as mental illness, changing perceptions regarding the course of the stigma may be particularly difficult, as there are not necessarily clear indicators of the course of such a stigma (Jones et al., 1984). Therefore, improving attitudes and behaviors toward individuals with a mental illness may be quite difficult. Jones et al. (1984), however, cite 
the efforts of mental health associations' efforts in public messaging around the effectiveness of treatment as one way in which to improve observers' perceptions regarding the potential course of mental illness.

Disruptiveness refers to extent to which the stigma interferes with interactions and communications with others (Jones et al., 1984). Stone and Colella (1996) suggest that as disabilities are perceived as more disruptive, observers may feel greater negative affect toward such individuals as they are unsure how to interact with them. Regarding mental illness, Jones et al. (1984) suggest that disruptiveness is different from perceived severity of symptoms. Rather, they argue that the nervous behavior often associated with mental illnesses may be a driver of perceived disruptiveness and subsequent negative treatment of such individuals (Jones et al., 1984). For example, in an early series of experiments on workplace discrimination against individuals with mental illness, Farina and colleagues examined the impact of a prior mental illness and nervousness on perceived hireability (Farina, Felner, \& Boudreau, 1973; Farina, Murray, \& Groh, 1978; Farina \& Hagelauer, 1975). In these experiments, participants rated a confederate acting as a job applicant who was either described as a former psychiatric patient or not during conditions in which the confederate behaved in a "tense and nervous" or a "calm and relaxed" manner. Across these studies, the authors demonstrated that those who were nervous and tense were rated lower in perceived hireability. However, prior mental illness status had no impact on ratings (these findings held across applicant gender and multiple work contexts; Farina et al., 1973, 1978; Farina \& Hagelauer, 1975). 
Aesthetics refers to the extent to which the stigma is perceived as repellent, ugly, or upsetting in terms of its aesthetic qualities (Jones et al., 1984). The aesthetic nature of a stigma is argued to be important due to its relationship with negative affect and behavioral responses (e.g., disgust, repulsion, social rejection, exclusion from workgroup activities; Jones et al., 1984; Stone \& Colella, 1996). Individuals with mental illnesses may be more likely to be perceived as being disheveled, unkempt, or unclean — aesthetic perceptions that are likely related to more negative social outcomes for these individuals (see Schumacher, Corrigan, \& Dejong, 2003). Furthermore, certain psychiatric medications have side effects that may impact motor movements, including tardive dyskinesia (i.e., a condition in which facial muscles are impacted and the individual may grimace, appear to engage in chewing-like behaviors, or drool; see Hinshaw, 2006).

Origin refers to the perceived origin of the stigma. That is, the extent to which the individual with the stigma is perceived as responsible for having — or able to control - the stigma (Jones et al., 1984). With regard to mental illness, it may be that those who are perceived "at fault" (onset controllability) for their stigma may receive negative treatment as they are thought of as lacking the ability to control their emotions and behavior and thus may not be trusted to be able to follow organizational norms and policies (see Stone \& Colella, 1996). Although observers often form beliefs in regard to the perceived controllability of the stigma (and responsibility of the individual for holding the stigma), accurate information is often unavailable (which is particularly the case with disabilities such as mental illness; Jones et al., 1984) resulting in incorrect attributions in regard to controllability of the stigma. Mental health researchers, 
however, have found that interventions including education and increased contact with stigmatized individuals resulted in improved attributions regarding controllability of the stigma (Corrigan et al., 2001).

Peril refers to the perceived danger of the stigma, including the extent to which the danger is perceived as imminent and serious (Jones et al., 1984). Mental illness is often thought to elicit perceived danger or threat, which is related to more negative attitudinal and behavioral responses toward such individuals compared to stigmas which are perceived as less threatening (Jones et al., 1984; Stone \& Colella, 1996). Other forms of disability, such as conditions considered to be contagious (HIV/AIDS) are also perceived as particularly high in peril (Stone \& Colella, 1996). Prior researchers have found that individuals who believe mental illnesses are associated with more aggressive or dangerous behaviors are more likely to engage in discriminatory behaviors and social distancing (Corrigan et al., 2001; Crandall \& Reser, 2005; Feldman \& Crandall, 2007). Stone and Collela (1996) suggest that in workplace contexts, individual with mental illness (which they classify as being perceived as a "dangerous" disability) will be less likely to be assigned to jobs requiring autonomy, teamwork, or high levels of responsibility and will experience more exclusion and resentment from coworkers. Further, because individuals with mental illness may be viewed as dangerous in workplace contexts, social support and relationships may degrade once an individual's mental illness status becomes known (Krupa et al., 2009).

To date, very little of the workplace literature has sought to better understand the role of these six dimensions of stigma and their impact on coworker and manager biases 
and behaviors. Much of the work that has been done often focuses on only two of these dimensions: concealability (see Jones \& King, 2014) and origin (controllability; e.g., King, Shapiro, Hebl, Singletary, \& Turner, 2006), and manipulates or holds constant, rather than directly measures perceptions of these dimensions (e.g., Hebl, Foster, Mannix, \& Dovidio, 2002; King et al., 2006; Martinez et al., 2016). Better understanding of the influence of these stigma dimensions, particularly with regard to different types of mental illness (e.g., depression versus anxiety), may help inform more inclusive business practices and relationship building opportunities, and may also spur an interest in expanding the workplace diversity and inclusion literature through the empirical demonstration of the importance of examining Jones et al.'s (1984) full set of stigma dimensions along with providing a framework for future measure developments or the potential for adapting the W-MISS to other stigmatized identities.

\section{Observer Stigma Perceptions and Behavioral Outcomes}

Understanding observer's perceptions of the dimensions of stigma is integral to predicting and changing behavioral outcomes for stigmatized individuals in the workplace. Regarding mental illness, there are negative cognitive (stereotypic) and behavioral (discriminatory) outcomes that are directed toward those with a mental illness status (Schomerus et al., 2012). The term "stereotype" has been defined as "qualities perceived to be associated with particular groups or categories of people" (Schneider, 2004, p. 24). Stigma perceptions can be thought of as highly related to stereotypes based on the extent to which observers view the stigma attributes as "a specific set of characteristics [that] is assumed to exist among people sharing the same stigma (i.e., the 
stigma evokes a social identity"; Biernat \& Dovidio, p. 89). For example, if an observer perceives those with mental illnesses to be dangerous, they would be engaging in stereotyping based on a stigma attribute.

Although stereotypes can result in negative consequences (making invalid assumptions about people), they are said to provide an important means for individuals to simplify the surrounding complex environment into pieces of information that can more easily be interpreted (Dovidio \& Gaertner, 2010). However, the endorsement of such stereotypes is often related to a host of differential behavioral outcomes directed toward members of the stereotyped group (Dovidio \& Gaertner, 2010). These specific differential behaviors toward — or treatment of - members of a social group is defined as discrimination, in terms of intergroup relations (Dovidio \& Gaertner, 2010). Although discrimination may also serve a functional role (i.e., to behaviorally respond to cognitive responses towards unknown others), more often than not the behavior is counterproductive.

As such, it may be said that individuals rely on stereotypes about others (which may be based on perceptions of attributes of their stigma) in order to simplify a host of unknown information, thus eliciting specific discriminatory behaviors. This is in line with Stone and Colella's (1996) theoretical model examining the factors that influence the workplace treatment of individuals with disabilities. Specifically, they argue that particular attributes of individuals with disability (including the nature of the disability [aesthetic qualities, danger or peril, course, origin, concealability, and disruptiveness]) influence observers treatment of the individuals with disabilities (e.g., job suitability 
ratings, job assignments, pay increases, training opportunities, mentoring, treatment as tokens, inclusion in workgroups, promotion, and helping behavior; Stone \& Colella, 1996).

Further, Stone and Colella (1996) argue that observers will automatically categorize individuals with disabilities into a particular "disability subtype" (in this case, mental illness), which will then result in observers drawing upon category-based stereotypes resulting in particular cognitions about traits, abilities, and personality characteristics of the target (i.e., individual who is being observed). Additionally, these category-based stereotypes allow observers to form anticipatory beliefs, such as how the target is expected to behave, which results in behavioral responses directed toward the target. As a result, observer behaviors toward the individual with the mental illness are likely to be biased and discriminatory. Consequently, the impact of stigma, and its behavioral responses on workers and the workplace, can be significant.

Stigma perceptions can also manifest in the form of categorization processes (Fiske \& Neuberg, 1990), by which targets are automatically categorized by observers using group-based categories and labels (e.g., "Black male") unless individuating information is known or provided. Without individuating information that is relevant to the observer, such as "Black male CEO", people are likely to perceive and treat the target according to their group categorization. This is especially relevant to understanding how people with mental illness are stigmatized and discriminated against within the workplace. In a similar example, stigma perceptions may lead targets to automatically 
categorize a worker with schizophrenia as the "employee with the mental illness"-a label that reduces the employee to merely one identity.

\section{Hypothesis Development}

The purpose of this study was to develop a measure of mental illness stigma using Jones et al.'s (1984) six stigma dimensions. This is important as stigma attributes are associated with negative cognitive, attitudinal, and behavioral outcomes (Jones et al., 1984; Stone \& Colella, 1996). Given that I proposed to use a deductive scale development approach with regard to item generation (i.e., SMEs generated items based on Jones et al.'s (1984) six stigma dimensions) and further proposed trimming items in an exploratory factor analysis sample, I hypothesized the following for the confirmatory factor analysis sample:

Hypothesis 1: A six factor model of the W-MISS in which the items are set to load onto their respective factors will fit significantly better than any combination of five-factor models $(\mathrm{Hl} l a)$, four-factor models $(H 1 b)$, three-factor models $(H 1 c)$, two-factor models $(H 1 d)$, or a single-factor model (Hle).

In order to begin to establish the nomological network of the W-MISS, I proposed to assess the convergent and discriminant validity of this measure with other theoretically relevant and disparate constructs. In particular, to establish convergent validity, I proposed to examine the W-MISS's relation to another general measure of mental illness stigma (Griffiths, Christensen, Jorm, Evans, \& Groves, 2004), along with two theoretically related measures: right-wing authoritarianism and social dominance orientation. Right-wing authoritarianism may be characterized as exhibiting "high 
degrees of deference to established authority, aggression toward out-groups when authorities permit that aggression, and support for traditional values when those values are endorsed by authorities" (Whitley, 1999, p. 126), and social dominance orientation has been defined as "the extent to which one desires that one's in-group dominate and be superior to out-groups" (Pratto, Sidanius, Stallworth, \& Malle, 1994, p. 742). These constructs are regularly used to demonstrate convergent validity with measures of stigma and prejudice, and prior researchers have demonstrated that these constructs are highly related to stigma, prejudice, and discrimination (see Whitley, 1999).

To establish the discriminant validity of the W-MISS, I proposed to examine its relation to measures of self-esteem, social desirability, and social support. Self-esteem has been defined as “one's belief regarding how well one is living up to the standards of value prescribed by the worldview" (Harmon-Jones et al., 1997, p. 24), and has been used as an indicator of discriminant validity of measures of stigmatization (e.g., Hill \& Willoughby, 2005; Walch, Ngamake, Francisco, Stitt, \& Shingler, 2012). Social desirability, a response tendency in which individuals attempt to endorse items in a manner in which they believe is socially desirable (Reynolds, 1982), is also a commonly used indicator of discriminant validity of measures of stigmatization (e.g., Chin, Fisak, \& Sims, 2002; Morrison \& O'connor, 1999; Walch et al., 2012). Social support (Zimet, Dahlem, Zimet, \& Farley, 1988) has been defined as the "perceived or actual instrumental and/or expressive provisions supplied by the community, social networks, and confiding partners" (Lin, 1986, p. 18), and has been used as an indicator of 
discriminant validity with measures of stigmatization (e.g., Luoma, O’Hair, Kohlenberg, Hayes, \& Fletcher, 2010).

I thus hypothesized the following:

Hypothesis 2: The W-MISS will demonstrate convergent validity (have a moderate correlation) with measures of general mental illness stigma $(H 2 a)$, rightwing authoritarianism $(H 2 b)$, and social dominance orientation $(H 2 c)$.

Hypothesis 3: The W-MISS will demonstrate discriminant validity (have a nonsignificant-small correlation) with measures of self-esteem $(H 2 a)$, social desirability $(H 2 b)$, and social support $(H 2 c)$.

To establish the predictive and incremental validity of the W-MISS, I proposed to examine the predictive ability of this measure on perceptions of hireability of individuals with a mental illness. The W-MISS has been developed to be specific to workplace mental illness stigma and draws upon theoretically important stigma content. Such a measure should demonstrate predictive validity as the content measured has been shown to align with relevant behavioral outcomes (see Ajzen \& Fishbein, 1977). Additionally, such a measure may more strongly predict workplace behavioral outcomes compared to a general measure of mental illness stigma as the frame of reference for the items will refer to a workplace context (Shaffer \& Postlethwaite, 2012). Therefore, I hypothesized the following:

Hypothesis 4: The W-MISS dimensions will predict hiring bias against individuals with mental illness $(\mathrm{H} 4 \mathrm{a})$ and will be a stronger predictor of 
perceptions of hireability compared to a general measure of mental illness stigma $(H 4 b)$.

Finally, as mental illnesses are quite varied in terms of their characteristics, it may be that particular mental illnesses elicit different perceptions of stigma. Theoretically, such difference may make sense, as subtypes are thought to elicit different cognitive, attitudinal, and behavioral responses (Fiske \& Neuberg, 1990). However, exactly how stigma perceptions and stigmatization of particular mental illnesses will operate remains theoretically and empirically unclear. I proposed to purposefully examine four specific mental illnesses due to their prevalence or cultural familiarity (i.e., depression, anxiety, substance use disorder, and schizophrenia). These four exemplar mental illnesses are appropriate to examine whether or not the W-MISS will remain as an important predictor of hireability, to compare this predictive power to a general measure of mental illness stigma, and to examine whether or not the relative importance of the dimensions will hold across types of mental illness. Thus, I asked the following research questions: Research Questions 1: Will there be differences in the stigma perceptions for individuals who are known to be diagnosed with depression $(R Q 1 a)$, an anxiety disorder $(R Q 1 b)$, substance use disorder $(R Q 1 c)$, or schizophrenia $(R Q 1 d)$ ? Research Question 2: Will the relative importance of the W-MISS dimensions and a general measure of mental illness stigma on hireability differ for individuals who are known to be diagnosed with depression $(R Q 2 a)$, an anxiety disorder $(R Q 2 b)$, substance use disorder $(R Q 2 c)$, or schizophrenia $(R Q 2 d) ?$ 
Research Question 3: Will the order of the relative importance of the W-MISS dimensions on hireability differ for individuals who are known to be diagnosed with depression $(R Q 3 a)$, an anxiety disorder $(R Q 3 b)$, substance use disorder $(R Q 3 c)$, or schizophrenia $(R Q 3 d) ?$ 


\section{Chapter 3: Study Method and Results}

The goal of this study was to develop and provide initial evidence for reliability and validity of a new measure of mental illness stigma based on Jones et al.'s (1984) dimensions. To do so, I drew upon recommendations largely from DeVellis (2003) and Hinkin (1998) in terms of study design. In particular, I used six phases and collected seven separate samples: (Phase 1) item generation, (Phase 2) content validation/item reduction, (Phase 3) exploratory factor analysis, (Phase 4) confirmatory factor analysis, (Phase 5) convergent/discriminant validity, and (Phase 6) predictive validity. My final goal was to develop a scale with six dimensions and approximately four items per dimension (Hinkin, 1998).

\section{Phase 1: Item Generation}

As the final goal of the measure development was to obtain four quality items per dimension (in line with recommendations by Harvey, Billings, \& Nilan, 1985; Hinkin, 1998), and as approximately $50 \%$ of the originally generated items are expected to be retained (Hinkin, 1998), I recruited 10 subject matter experts and asked each to develop at least five items per dimension (potentially 300 items). The high number of items allowed for highly overlapping items (each subject matter expert was unaware of the items developed by one another) or poorly worded items to be removed.

Sample. Ten subject matter experts (SMEs) in the area of workplace diversity, mental health, and mental illness, along with individuals who have experience with managing a mental illness identity in the workplace, were asked to assist with the generation of items for this study. Of these, four faculty members in Management, 
Hospitality Management, or Applied Psychology, one doctoral-level practitioner in the area of workplace diversity, and three graduate students in Applied Psychology returned completed responses. This sample was in line with recommendations by Hinkin (1998) in terms of expertise.

Design. As the theoretical foundation for the construct is clearly defined, a deductive scale development approach was utilized (Hinkin, 1998). In a deductive scale development approach, the theoretical foundation of the phenomenon can be ascertained from the prior literature and provides sufficient background to develop an initial pool of items (see Hinkin, 1998). When using such an approach, a definition of the phenomenon is used in order to develop the pool of items (Schwab, 1980). Therefore, I provided SMEs with the following definitions for each stigma dimension outlined by Jones et al. (1984):

Concealability: The extent to which the stigma is hidden or obvious and the extent to which its visibility is perceived as controllable.

Course: The extent to which the stigma may or may not change over time and the perceived ultimate outcome of the stigma.

Disruptiveness: The extent to which the stigma blocks or hampers interactions and communications with others.

Aesthetics: The extent to which the stigma is perceived as repellent, ugly, or upsetting in terms of its aesthetic qualities.

Origin: The perceived origin of the stigma. That is, the extent to which the individual with the stigma is perceived as responsible for having the stigma (often thought of as the perceived controllability of the stigma).

Peril: The perceived danger posed by the stigma, including the extent to which the danger is perceived as imminent and serious. 
In line with Hinkin's (1998) and DeVellis' (2003) recommendations for item development, SMEs were instructed to attempt to write exemplar items of each dimension in reference to the stigma of mental illness with a number of guidelines. First, items should utilize clear and concise statements. Second, items should be written with language that would be considered familiar to most respondents. SMEs were instructed to avoid jargon, expressions, and colloquial language (Spector, 1992). Additionally, items should be written at a high school reading level or below in order to allow flexibility in use of the items (DeVellis, 2003). Third, items should remain consistent in perspective (i.e., should not mix affective and behavioral responses; Harrison \& McLaughlin, 1993). As I was interested in assessing stereotypic beliefs about individuals with regards to stigma dimensions, SME's were instructed to provide items that reflected stereotypic cognitions regarding each of the dimensions.

Fourth, each single item should address a single stereotypic cognition; doublebarreled items should be avoided. Fifth, SMEs were instructed that item redundancy may be useful if the items are redundant in terms of general content but differ in structure and with regard to the particular terminology used (as recommended by DeVellis, 2003). This recommendation is important as items that are written in a highly overlapping fashion may generate only small amounts of variance and may also result in negative psychometric outcomes (e.g., correlated error terms; see Brown \& Moore, 2012).

Sixth, SMEs were reminded to avoid leading items. Although the items are addressing stereotypic cognitions, they should be written in such a way that they are assessed as generally "neutral" so that participants may more freely choose to endorse 
specific items. Seventh, SMEs were instructed to avoid providing negatively-worded items. Although reverse-scoring items remains a technique for researchers to attempt to lower response-set bias and inattentive responding (e.g., McKiernan, Spreadbury, Carr, \& Waller, 2013; Price \& Mueller, 1986), the psychometric costs of utilizing such items seem to outweigh their benefits. For example, reverse-scored items often load onto a separate "method" factor (DiStefano \& Motl, 2006). Furthermore, other remedies are available, such as providing instructed response items or bogus items interspersed in the survey to assess the level of inattentiveness (Meade \& Craig, 2012). See Appendix A for the full set of instructions provided to SMEs.

Further, each SME independently developed items without having access to any other SMEs pool of developed items. I made this decision so that no SME would be influenced by having seen any other pool of developed items. Although this process was expected to result in some level of redundancy, I oversampled in terms of total number of items in order to allow for the removal of highly redundant items or of items that did not follow the psychometric guidelines provided to SMEs.

This process resulted in a total of 193 items developed by the SMEs. These items were then screened by two SMEs (a faculty member in applied psychology and me) to make sure that they followed the guidelines listed above. Items were then evaluated by the same two SMEs for redundancy and quality (e.g., double-barreled items were modified or removed), resulting in a pool of 80 items. 


\section{Phase 2: Content Validation/Item Reduction}

Having obtained an initial pool of items, I then moved on to examine the content validity of these items to identify conceptually inconsistent or poorly worded items (Hinkin, 1998). In particular, I examined content adequacy with an item sorting task and further reduced items by evaluating their relevancy and clarity.

Phase 2a: Content adequacy sample. One hundred twenty-six participants in the US were recruited from Amazon's MTurk. MTurk is an online crowdsourcing work platform that allows "requesters" (individuals who create tasks) to connect with "workers" (individuals who are nominally compensated for completing tasks). Specifically, workers can browse a series of tasks that they may choose to complete based on their backgrounds and interests and then receive compensation for the completion of tasks. As these tasks can include the completion of surveys or other contained research tasks (survey platforms such as Qualtrics can be integrated into the MTurk platform), MTurk has been gaining popularity as a research tool among social scientists (Buhrmester, Kwang, \& Gosling, 2011; Buhrmester, Talaifar, \& Gosling, 2018).

In terms of data quality, Feitosa, Joseph and Newman (2015) have shown that MTurk samples collected in the US demonstrate measurement invariance with both workplace and student samples on highly validated measures. Further, Walter, Seibert, Goering, and O'Boyle Jr (2018) have found meta-analytic evidence that online panel data (including MTurk) demonstrated similar internal reliability estimates for popular scales and similar effect size estimates for IV-DV relations compared to conventionally sourced 
applied psychology samples. Although evidence does exist regarding the quality of data collected from MTurk for research purposes, a sample should always be scrutinized for its appropriateness for any given research question and design. MTurk's platform allows for workers from a variety of backgrounds, job statuses, organizations, and industries. Given the goal of developing a workplace mental illness stigma measure that may be generalized across organizations and industries along with the nature of the item sorting task, I determined that such a sample was appropriate.

Also, as I was interested in developing a measure that could be used by managers, I sought out to obtain a sample of working adults with management experience. In order to do so, I used Smith et al.'s (2015) screening technique. Specifically, before disclosing any inclusion criteria, I began the survey with a short series of demographic items with inclusion items embedded, including whether or not the participant had management experience, was currently working and, if so, how many hours the participant worked per week. The survey included specific threading criteria such that only those who identified themselves as meeting the predetermined inclusion criteria were able to continue (individuals who did not meet criteria were blocked from re-entering the survey). This is an important consideration with MTurk, as workers can select into any number of surveys based on their description, which may raise concerns regarding how honest workers may be regarding their background for inclusion criteria. I took steps to avoid such concerns by concealing the criteria for inclusion. By using Smith et al.'s (2015) screening technique, of the original 126 participants recruited for this sample, a total of 71 participants identified themselves as having management experience and identified that 
they were working at least 20 hours per week. This final sample of 71 participants were allowed to continue to the full survey.

Additionally, another consideration in terms of promoting data quality is screening for inattentive responding. Inattentive responding may include random responding, speeding, not carefully reading items, etc. (see Mead \& Craig, 2012). One strategy that is suggested as a best practice by Mead and Craig (2012) in order to promote data quality and guard against inattentive responding is the utilization of instructed response items. Specifically, in the survey I embedded a series of three instructed response items (e.g., "Please select Peril for this answer") to identify and "flag" inattentive responders. Data from any participant who incorrectly responded to any one of these three items (i.e., selected one of the other response options) were removed before data analysis. Twenty-four participants did not respond to at least one of the three instructed response items correctly, resulting in a final sample of 47 individuals $\left(M_{\text {Age }}=\right.$ $34.23, S D_{\text {Age }}=8.88 ; 38 \%$ Women; $68 \%$ White; $M_{\text {Years Employed }}=13.21, S D_{\text {Years Employed }}=$ 9.03) to assess the content adequacy of the items. The demographic characteristics of this sample appeared in line with my expectations (typically, I have found that working samples collected on MTurk tend to have an average age around mid-thirties, with a majority of White men).

This is an appropriate sample — in terms of size and source — as only a small number of raters who do not need to have an in-depth understanding of the phenomenon of interest are required for this task (Anderson \& Gerbing, 1991; Schriesheim et al., 1993). Indeed, in prior work by Anderson and Gerbing (1991) and Schriesheim, Powers, 
Gardiner, and Lankau (1993), they sampled between 40 and 65 participants for this task, respectively. Further, such a sample is in line with recommendations from Hinkin (1998).

Design and results. Participants were presented with definitions of the dimensions and were asked to match individual items with each of the dimensions. Additionally, an "unclassified" category was included so that participants could choose to identify an item as not representing any of the dimensions. In line with Hinkin's (1998) recommendations, items were evaluated for content validity with Anderson and Gerbing's (1991) proportion of substantive agreement (defined as the number of respondents who classified an item to its intendent construct over the total number of respondents). Items that resulted in a proportion of substantive agreement greater than .5 were retained (Anderson \& Gerbing, 1991), resulting in 64 items being retained.

Phase 2b: Item reduction sample. To further evaluate content validity, a total of 11 SMEs in the area of workplace diversity and mental health, and individuals who have experience with managing a mental illness identity in the workplace, were recruited in order to assist with screening items for relevance and clarity (see DeVellis, 2003). Of these, five faculty members in Management or Applied Psychology and two graduate students in Applied Psychology returned completed responses.

Design and results. SMEs were directed to a survey in which they were asked to identify how "relevant" and "clear" each of the items were (on a unipolar scale from 1 (not at all) through 7 (extremely)) with regard to the stigma dimension that they represent. Items that were rated as relatively lower on relevance and/or clarity were 
examined and removed, as deemed appropriate by two SMEs (a faculty member in applied psychology and me), in line with recommendations by DeVellis (2003). This process resulted in 59 items with average ratings of at least " 4 " or more being retained.

\section{Phase 3: Exploratory Factor Analysis}

I then further sought out to refine the resulting item pool with a series of exploratory factor analyses. My goal was to obtain four items per factor.

Sample. To evaluate the factor structure of the developed items with exploratory common factor analysis, I sought a sample of 300 working adults in the US from Amazon's MTurk. Although recommendations for sample size should be considered heuristics or rules of thumb, some guidance has been provided in terms of generally acceptable sample sizes for obtaining accurate solutions with exploratory factor analysis. For example, recommendations for appropriate sample size for exploratory factor analysis range from an item-to-response ratio of 1:4 (Rummel, 1970) to 1:10 (Schwab, 1980). Others have found that samples of 150 should provide an accurate solution given fairly strong item correlations (Guadagnoli \& Velicer, 1988). As I retained 59 items, I sampled 300 participants with an item-to-response ratio of approximately 1:5 for the exploratory factor analysis.

In all, I recruited 779 participants from Amazon's MTurk. I again used Smith et al.'s (2015) screening technique to ensure that participants were working adults with management experience, resulting in a sample of 371 participants. Again, I used three instructed response items (e.g., "Please select agree very much") as recommended by Meade and Craig (2012). Participants who did not correctly answer all three of the 
instructed response items were not included for data analysis, resulting in a final sample of 300 participants $\left(M_{\mathrm{Age}}=37.83, S D_{\mathrm{Age}}=11.32 ; 56 \%\right.$ Women; $68 \%$ White; $M_{\text {Years }}$ Employed $\left.=17.32, S D_{\text {Years Employed }}=11.85\right)$. This sample is demographically similar to the prior content adequacy sample (slightly older, a higher percentage of women, longer average years employed).

Design. Participants were instructed to provide ratings of the extent to which they agreed with the survey items on a 7-point unipolar scale $(1=$ "agree not at all," $7=$ "agree very much"). Participants were reminded that there is no right or wrong answer to any of the items and that their survey responses will be kept completely anonymous so as to help avoid social desirability bias. Participants were then presented with each of the generated items and were asked to respond to demographic questions at the end of the survey, at which point they were thanked and debriefed.

Results. I used SPSS to perform initial exploratory factor analyses. All items were first examined and were found to meet assumptions of normality (standardized skweness $\leq|1.59|$ and standardized kurtosis $\leq|1.18|$; Hair, Black, Babin, \& Anderson, 2009). Additionally, the inter-item correlations of the variables were examined for each factor. All items were well above the recommendation of $r<.40$ for removal (in all cases, $r>0.51$; Kim \& Mueller, 1978). I then ran an initial principal components analysis and examined Bartlett's (1950) test of sphericity $(p<.001)$ and the KaiserMeyer-Olkin measure of sampling adequacy $(\mathrm{KMO}=.95$; acceptability is > .60; Tabachnick \& Fidell, 2012), confirming the factorability of the data matrix. To determine how many factors to extract, I drew upon my theoretical model of six factors. 
Notably, although in the initial factor analysis six factors demonstrated eigenvalues over 1 (a rule of thumb for empirically deciding how many factors to extract by Tabachnick \& Fidell, 2012), as items were removed this rule of thumb was not met. However, as I had a strong theoretical and methodical rationale (items were generated based on Jones et al.'s (1984) six dimensions), and results at each step produced interpretable solutions (see Tabachnick \& Fidell, 2012), I continued to extract six factors at each step.

Further, I used a common-factor analysis with maximum-likelihood extraction. This is due to the fact that I was interested in the latent constructs for each factor (Hinkin, 1998) and responses to each item demonstrated relative normality (Hair et al., 2009). Additionally, as I expected the factors to be correlated, Promax rotation (Hendrickson \& White, 1964), an oblique rotation, was used (DeVellis, 2003). An oblique rotation is preferable to an orthogonal rotation for a number of reasons including: (a) an oblique rotation allows for (but does not require) correlations among factors and will produce generally acceptable results even if the correlation across the factors is near zero (Harman, 1976); and (b) oblique rotations will produce correlation values among the factors that can be assessed (Fabrigar, Wegener, MacCallum, \& Strahan, 1999). Although there is not a dominant technique for oblique rotation, several commonly used rotations have been found to produce satisfactory results, including Promax rotation (Fabrigar et al., 1999). At each step, items were retained that demonstrated factor loadings greater than .40 with no cross-loadings greater than .30 (Ford, MacCallum, \& Tait, 1986; Hinkin, 1998; Worthington \& Whittaker, 2006). This iterative process resulted in four remaining items for each of the six factors (see Table 2). Reliabilities 
surpassed acceptable levels for each factor (Gerbing \& Anderson, 1988; Nunally, 1978): concealability $(\alpha=.92)$, course $(\alpha=.91)$, disruptiveness $(\alpha=.97)$, aesthetics $(\alpha=.93)$, origin $(\alpha=.97)$, peril $(\alpha=.95)$.

\section{Phase 4: Confirmatory Factor Analysis}

Having obtained a final pool of four items per factor, I sought out to confirm the factor structure in a separate sample by examining a series of models with confirmatory factor analysis. Confirmatory factor analysis allows for the goodness of fit of the hypothesized model to be assessed (unlike in traditional exploratory factor analysis) and allows for the comparison of the hypothesized multidimensional model to a series of alternative models in which dimensions are combined (in this case including alternative five-, four-, three-, two-, and single-factor models; see Hinkin, 1998). Further, using a separate sample allows to assess the replicability of the factor structure identified in the prior exploratory factor analysis sample (Hinkin, 1998).

Sample. I recruited 471 participants from Amazon's MTurk, and again used Smith et al.'s (2015) screening technique to include only participants who identified themselves as being working adults with management experience, resulting in a sample of 257 participants. To screen for inattentiveness, I again used three instructed response items (e.g., "Please select agree very much"; Meade \& Craig, 2012), resulting in a final sample of 200 participants $\left(M_{\mathrm{Age}}=36.60 ; S D_{\mathrm{Age}}=10.98 ; 57 \%\right.$ Women; $79 \%$ White; $\left.M_{\text {Years Employed }}=16.34 ; S D_{\text {Years Employed }}=12.97\right)$. This sample is demographically similar to the prior exploratory factor analysis sample (somewhat higher percentage White participants). For confirmatory factor analysis, several rules of thumb with regard to the 
required sample size required. Hinkin (1998) takes a conservative approach and recommends at least 200 complete responses. This recommendation is also above the minimum required sample of 161 participants based on a power analysis with an anticipated medium effect size (.30), statistical power set to .80 , with 6 latent variables, 24 observed variables, and a probability level of .05 (Soper, 2018).

Design. Similar to the exploratory factor analysis phase, participants were screened, and eligible participants were directed to the full survey. This survey included a 7-point unipolar scale ( $1=$ "agree not at all," 7 = "agree very much"). To help avoid social desirability bias, participants were reminded that there was no right or wrong answer to any of the items and that their survey responses were kept completely anonymous. At the end of the survey, demographics were again collected, at which point participants were thanked and debriefed.

Results. All items demonstrated acceptable levels of normality (all cases standardized skewness $\leq|1.20|$ and standardized kurtosis $\leq|1.19|$; see Kline, 2010). Nine respondents were missing one response, one respondent was missing two responses, and one respondent was missing four responses. Reliabilities again surpassed acceptable levels for each factor (Gerbing \& Anderson, 1988; Nunally, 1978): concealability ( $\alpha=$ $.91)$, course $(\alpha=.90)$, disruptiveness $(\alpha=.96)$, aesthetics $(\alpha=.91)$, origin $(\alpha=.97)$, peril $(\alpha=.93)$. As all items demonstrated acceptable levels of reliability and normality and as data missingness is a common concern in such frameworks, I used full information maximum likelihood estimation (Kline, 2010). 
I specified a model using the Lavaan package in $\mathrm{R}$ in which each item was set to load onto its respective hypothesized latent factor, and each latent factor was allowed to correlate. As chi-square is sample size dependent (Jöreskog \& Sörbom, 1989), I assessed goodness of fit with fit indices including CFI, RMSEA, SRMR, and TLI using recommendations from $\mathrm{Hu}$ and Bentler (1999) and found support for the hypothesized six-factor model, $\chi^{2}(237)=457.20, p<.001, \mathrm{CFI}=.96, \mathrm{RMSEA}=.07, \mathrm{TLI}=.95$, SRMR $=.05$ (see Figure 1 for standardized factor loadings). To examine Hypothesis 1 (i.e., a six factor model of the W-MISS in which the items are set to load onto their respective factors will fit significantly better than any combination of five-factor models (HIa), four-factor models $(H 1 b)$, three-factor models $(H 1 c)$, two-factor models $(H 1 d)$, or a single-factor model $(H l e)$ ), I then tested a series of alternative models including five-, four-, three-, two-, and one-factor models. Based on a series of a chi-square difference tests, I found that each of these models fit significantly worse than the hypothesized model, supporting Hypothesis 1 (see Table 3).

\section{Phase 5: Convergent and Discriminant Validity}

Having obtained evidence for valid factor structure of the 24 items, I proceeded to test for convergent and discriminant validity. Examining convergent validity (the extent that measures correlate with other theoretically similar measures) and discriminant validity (the extent that measures do not correlate with other theoretically dissimilar measures) is particularly important for gathering additional evidence of construct validity (Hinkin, 1998). 
Sample. I recruited 240 participants from Amazon's MTurk. Using Smith et al.'s (2015) screening technique, I only invited participants who identified themselves as working adults with management experience to continue to the full survey, resulting in a sample of 122 participants. I then screened for careless respondents using three instructed response items (e.g., "Please select agree very much"; Meade and Craig, $2012)$, resulting in a final sample of 101 participants $\left(M_{\mathrm{Age}}=34.10 ; S D_{\mathrm{Age}}=9.40 ; 58 \%\right.$ Women; $73 \%$ White; $\left.M_{\text {Years Employed }}=14.10, S D_{\text {Years Employed }}=9.51\right)$. Based on recommendations by Schmitt and Stults (1986), this sample size is appropriate for this purpose.

Design. After passing the screening questions, participants were presented with items from seven scales (see Appendix B for a full list of scales and items), including the newly developed W-MISS. After responding to these items, participants provided demographic information, and were thanked and debriefed. Participants received the same instructions as the prior exploratory and confirmatory factor analysis phases.

Convergent validity measures. To assess convergent validity, participants responded to items modified from the Depression Stigma Scale (Griffiths et al., 2004), a shortened form of Altemeyer's (1981) Right-Wing Authoritarianism Scale (Zakrisson, 2005), and the Social Dominance Orientation Scale (Pratto et al., 1994).

General stigma toward mental illness. A general scale of stigma toward mental illness was adapted from the 9-item personal depression subscale from the Depression Stigma Scale (Griffiths et al., 2004). The scale uses a 7-point bipolar scale $(1=$ "Strongly Disagree," 7 = "Strongly Agree") and was modified to address mental illness 
by using the term "mental health problem" in place of "depression." Participants were provided with the following instructions: "Please respond with the extent to which you agree with the following items on a 7-point scale $(1=$ 'Strongly Disagree,' $7=$ 'Strongly Agree')" and then were asked to respond to each item. Items include: "People with mental health problems could snap out of it if they wanted," "Mental health problems are a sign of personal weakness," "Mental health problems are not a real medical illness", "People with mental health problems are dangerous," "It is best to avoid people with mental health problems so you don't develop the problem," People with mental health problems are unpredictable," "If I had a mental health problem I would not tell anyone," "I would not employ someone if I knew they had a mental health problem," and "I would not vote for a politician if I knew they had a mental health problem." This modified scale has been shown to demonstrate acceptable levels of reliability $(\alpha=.74-.81$; Dimoff, Kelloway, \& Burnstein, 2016).

Right-wing authoritarianism. A revised and shortened version of Altemeyer's (1981) 30-item Right-Wing Authoritarianism Scale was used. This scale, developed and validated by Zakrisson (2005) is comprised of 15 items. The scale was presented on a 7point bipolar scale ( 1 = "Strongly Disagree," 7 = "Strongly Agree"). These items were modified from the original scale such that they were generally shortened, referred to "society" rather than "country" to avoid the construct of nationalism, and extreme wording was replaced in order to increase variability in endorsement of these items. This scale was found to demonstrate acceptable levels of reliability $(\alpha=.72)$ and to be related 
to theoretically relevant constructs (social dominance orientation, modern racism, modern sexism; Zakrisson, 2005).

Participants were provided with the following instructions, "Please respond with the extent to which you agree with the following items on a 7-point scale ( $1=$ 'Strongly Disagree', 7 = 'Strongly Agree')" and then were asked to respond to each item. The final set of items included: "Our country needs a powerful leader, in order to destroy the radical and immoral currents prevailing in society today," "Our country needs free thinkers, who will have the courage to stand up against traditional ways, even if this upsets many people (R)," “The 'old-fashioned ways' and 'old-fashioned values' still show the best way to live," "Our society would be better off if we showed tolerance and understanding for untraditional values and opinions" (R), “God's laws about abortion, pornography and marriage must be strictly followed before it is too late, violations must be punished," "The society needs to show openness towards people thinking differently, rather than a strong leader, the world is not particularly evil or dangerous" (R), "It would be best if newspapers were censored so that people would not be able to get hold of destructive and disgusting material," "Many good people challenge the state, criticize the church and ignore "the normal way of living"" (R), "Our forefathers ought to be honored more for the way they have built our society, at the same time we ought to put an end to those forces destroying it," "People ought to put less attention to the Bible and religion, instead they ought to develop their own moral standards" (R), "There are many radical, immoral people trying to ruin things; the society ought to stop them," "It is better to accept bad literature than to censor it" (R), "Facts show that we have to be harder against 
crime and sexual immorality, in order to uphold law and order," "The situation in the society of today would be improved if troublemakers were treated with reason and humanity" (R), and "If the society so wants, it is the duty of every true citizen to help eliminate the evil that poisons our country from within."

Social dominance orientation. Social dominance orientation was measured with Pratto, Sidanius, Stallworth, and Malle's (1994) scale, which consists of 16 items and demonstrated acceptable levels of reliability $(\alpha=.93)$. The scale was presented on a 7point bipolar scale ranging from 1 = "Extremely Negative" to 7 = "Extremely Positive." Participants were provided with the following instructions, adapted from the original distribution of the scale: "Which of the following objects or statements do you have a positive or negative feeling towards? Beside each object or statement, select the number from ' 1 ' (Extremely Negative) to '7' (Extremely Positive) which represents the degree of your positive or negative feeling."

Items included: "We should strive to make incomes as equal as possible" (R), “Group equality should be our ideal" (R), "It's OK if some groups have more of a chance in life than others," "To get ahead in life, it is sometimes necessary to step on other groups," "We should do what we can to equalize conditions for different groups" (R), "It's probably a good thing that certain groups are at the top and others are at the bottom," "Inferior groups should stay in their place," "We would have fewer problems if groups were treated more equally" (R), "It would be good if groups could be equal" (R), "In getting what you want, it is sometimes necessary to use force against other groups," "All groups should be given an equal chance in life" (R), "If certain groups stayed in their 
place, we would have fewer problems," "We should strive for increased social equality" (R), "Sometimes other groups must be kept in their place," "Some groups of people are simply inferior to other groups," "No one group should dominate in society" (R).

Discriminant validity measures. To assess discriminant validity, participants responded to items modified from the Rosenberg Self-Esteem Scale (1979), a shortened version of the Marlowe-Crowne Social Desirability Scale (Reynolds, 1982), and the Multidimensional Scale of Perceived Social Support (Zimet et al., 1988).

Self-esteem. Self-esteem was measured with the Rosenberg Self-Esteem Scale (1979). This scale consists of 10 items and has been shown to have acceptable levels of reliability (average $\alpha=.81$; D. Schmitt \& Allik, 2005). Participants were provided with the following instructions, "Below is a list of statements dealing with your general feelings about yourself. Please indicate how strongly you agree or disagree with each statement," and will be asked to respond on a 7-point scale ( 1 = 'Strongly Disagree' to 7 $=$ 'Strongly Agree')."

Items included, "On the whole, I am satisfied with myself," "At times I think I am no good at all" (R), "I feel that I have a number of good qualities," "I am able to do things as well as most other people, "“ "I feel I do not have much to be proud of" (R), "I certainly feel useless at times" (R), "I feel that I'm a person of worth, at least on an equal plane with others," "I wish I could have more respect for myself" (R), "All in all, I am inclined to feel that I am a failure" (R), and "I take a positive attitude toward myself" (Rosenberg, 1979). 
Social desirability. Social desirability was assessed with a shortened version of the original Marlowe-Crowne Social Desirability Scale (Reynolds, 1982). The original scale consisted of 30-items presented with response options "True" or "False" (Crowne \& Marlowe, 1960). I utilized Reynolds' (1982) form C, which includes 13 items from the original scale. This version of the scale has been shown to be highly correlated with the original scale $(r=.93)$ and demonstrate acceptable levels of reliability (KR-20 = .76). The items were presented on a 7-point bipolar scale (1 = "Strongly Disagree," $7=$ "Strongly Agree"). Participants were provided with the following instructions: "Please indicate how strongly you agree or disagree with the following items on a 7-point scale (1 $=$ 'Strongly Disagree,' 7 = 'Strongly Agree').”

Items included, "It is sometimes hard for me to go on with my work if I am not encouraged” (R), "I sometimes feel resentful when I don’t get my way” (R), “On a few occasions, I have given up doing something because I thought too little of my ability" (R), "There have been times when I felt like rebelling against people in authority even though I knew they were right" (R), "No matter who I'm talking to, I'm always a good listener," "There have been occasions when I took advantage of someone" (R), "I'm always willing to admit it when I make a mistake," "I sometimes try to get even rather than forgive and forget" (R), "I am always courteous, even to people who are disagreeable," "I have never been irked when people expressed ideas very different from my own," "There have been times when I was quite jealous of the good fortune of others" (R), "I am sometimes irritated by people who ask favors of me" (R), and "I have never deliberately said something that hurt someone's feelings." 
Social support. Social support was assessed with the Multidimensional Scale of Perceived Social Support (Zimet et al., 1988). This scale consisted of 12-items and three subscales, which together form an overall index of perceived social support, which has been shown to demonstrate acceptable levels of reliability $(\alpha=.85$; Zimet et al., 1988). Participants were provided with the following instructions, "Please indicate the extent you agree or disagree with the following items." The items were presented on a 7-point bipolar scale (1 = "Strongly Disagree," 7 = "Strongly Agree").

Items include, "There is a special person who is around when I am in need," "There is a special person with whom I can share my joys and sorrows," "My family really tries to help me," "I get the emotional help and support I need from my family," "I have a special person who is a real source of comfort to me," "My friends really try to help me," "I can count on my friend when things go wrong," "I can talk about my problems with my family," "I have friends with whom I can share my joys and sorrow," "There is a special person in my life who cares about my feelings," "My family is willing to help me make decisions," and "I can talk about my problems with my friends."

Results. To test Hypotheses 2 (The W-MISS will demonstrate convergent validity (have a moderate correlation) with measures of general mental illness stigma $(H 2 a)$, right-wing authoritarianism $(H 2 b)$, and social dominance orientation $(H 2 c))$ and Hypothesis 3 (The W-MISS will demonstrate discriminant validity (have a nonsignificant - small correlation) with measures of self-esteem $(H 3 a)$, social desirability $(H 3 b)$, and social support $(H 3 c))$, I utilized a modified version of Campbell and Fiske's (1959) multitrait multimethod matrix. In particular, I obtained Pearson $r$ correlations for each of 
the measures and assessed the correlations of closely related and more distant constructs, including the W-MISS dimensions, the general stigma toward mental illness scale, rightwing authoritarianism, social dominance orientation, self-esteem, social desirability, and social support (see Table 4).

In partial support of Hypothesis 2, I found that the W-MISS dimensions demonstrated significant intercorrelations with the general stigma toward mental illness scale $(r=.26-.83 ; H 2 a)$, however for right-wing authoritarianism, neither concealability nor disruptiveness were significantly related (the remaining dimensions were related at $r$ $=.21-.42 ; H 2 b)$, and concealability was not significantly related to social dominance orientation (the remaining dimensions were related at $r=.26-.54 ; H 2 c$ ).

In partial support of Hypothesis 3, I found that the W-MISS dimensions demonstrated small to medium significant intercorrelations with the self-esteem measures $(r=-.20--.33 ; H 3 a)$, however none of the W-MISS dimensions were significantly related to the measure of social desirability $(r=-.03--.19 ; H 3 b)$ or to the measure of social support $(r=-.05--.19 ; H 3 c)$.

\section{Phase 6: Predictive Validity}

To further gather evidence for construct validity, predictive or criterion related validity should be examined (Hinkin, 1998). To do so, I examined the criterion related validity of the W-MISS dimensions to a measure of hireability in regard to an ostensible job candidate with a mental illness. Theoretically, stigma perceptions across Jones et al.'s (1984) dimensions should be related to discriminatory treatment of individuals with 
a mental illness (i.e., the stronger the stigma perceptions, the lower the hireability ratings).

Sample. I recruited 1264 participants from Amazon's MTurk. I again used Smith et al.'s (2015) screening technique, only inviting participants who identified themselves as working adults with management experience to continue to the full survey, resulting in a sample of 615 participants. I then screened for careless respondents using three instructed response items (e.g., "Please select agree very much"; Meade and Craig, 2012), resulting in a sample of 419 participants. Finally, participants were provided with a manipulation check at the end of the survey (described in detail later). Participants who did not pass the manipulation check were removed, resulting in a final sample of 365 individuals (between $64-75$ participants per condition; $M_{\text {Age }}=37.57, S D_{\text {Age }}=10.41$; 44\% Women; $77 \%$ White; $\left.M_{\text {Years Employed }}=16.58, S D_{\text {Years Employed }}=11.87\right)$. This sample size is appropriate, as I expected between a small and medium effect of the predictors on perceived hireability. In a simulation study, this sample size has been shown to demonstrate appropriate power and relatively small bias to evaluate the relative importance of the proposed predictors on an outcome (Tonidandel, LeBreton, \& Johnson, 2009).

Design. Participants were presented with a short series of screening questions. After passing the screening questions, participants were randomly assigned to evaluate the hireability of a job candidate known to be diagnosed with depression, anxiety, substance use disorder, or schizophrenia. These four mental illnesses were chosen to examine as depression and anxiety are the most common mental illnesses in the working 
population (MHCC, 2011) and substance use disorder and schizophrenia are commonly referenced in popular culture.

Specifically, participants were told that they will be shown a resume for the candidate, and then were asked to assign ratings to the candidate. Participants were then randomly assigned to view one of five resumes (see Appendix C). All aspects of the resume were held constant across conditions, with one exception. In each case the applicant had a gap in their employment, and participants were randomly assigned to view one of the following messages at the top of the resume, "Please note: There is a gap in my resume because I was diagnosed with (a mental illness, depression, anxiety, substance use disorder, or schizophrenia) and could not work due to medical treatment." This stimulus has been validated and was used in Martinez et al. (2016), but in reference to a cancer diagnosis. Additionally, the name of the applicant was changed to be gender and race neutral (i.e., "Taylor Johnson"). Participants then responded to the hireability items, followed by the stigma item. Then, participants were provided with a manipulation check in which they were asked to identify the reason that the ostensible job candidate gave for having an employment gap on their resume in a single open-ended question. Finally, participants provided demographic information, and were thanked and debriefed.

Measures. In order to assess the predictive validity of the W-MISS, participants provided responses to the W-MISS (as measured in the convergent and discriminant validity phase), a modified version of the general stigma toward depression scale (as measured in the convergent and discriminant validity phase; Griffiths et al., 2004), and a 
measure of hireability (Hebl \& Skorinko, 2005) in reference to individuals with mental illness (see Appendix B for a full list of scales and items).

Hireability. Perceived hireability was assessed with nine items modified from Hebl and Skorinko (2005). Participants were provided with the following instructions, "Please consider the job candidate when responding to the following, and rate the extent to which you agree with each item on a 7-point scale ( 1 = 'Strongly Disagree,' $7=$ 'Strongly Agree')." Participants then answered the following nine items, "I would recommend hiring the applicant," "I viewed the applicant as a quality candidate," "I liked the applicant as a potential employee," "I liked the applicant personally," "I felt the applicant would do well in a workplace scenario," "I anticipated the applicant would have on-the-job problems" (R), "I thought hiring the job applicant would be too risky" (R), "I thought the applicant would be a competent worker," and "I felt there were too many red flags with the applicant" (R).

Results. To test Hypothesis 4 (The W-MISS dimensions will predict hiring bias against individuals with mental illness $(\mathrm{H} 4 \mathrm{a})$, and will be a stronger predictor of perceptions of hireability compared to a general measure of mental illness stigma $(H 4 b))$, I examined intercorrelations and ran a series of multiple regression analyses.

In particular, to test $H 4 a$, I examined the intercorrelations between the W-MISS dimensions and perceived hireability of the applicant known to have "a mental illness." $\mathrm{H} 4 \mathrm{a}$ was partially supported as concealability was significantly positively related to hireability $(r=.27, p<.05)$, and course $(r=-.42, p<.05)$, disruptiveness $(r=-.62, p<$ $.05)$, origin $(r=-.26, p<.05)$, and peril $(r=-.43, p<.05)$ were significantly negatively 
related to hireability; however, the aesthetic dimension $(r=-.19, p<.10)$ was only marginally significantly related to hireability.

To test $H 4 b$ and examine the incremental validity of the W-MISS dimensions above and beyond the general measure of mental illness stigma on hireability perceptions, I ran a series of six regression analyses with hireability as the dependent variable, general mental illness stigma added as the independent variable in step 1, and each W-MISS dimension added in step 2. To support $H 4 b$, I expected the $\Delta R^{2}$ to be significant at step 2 for each dimension. $H 4 b$ was also partially supported as only course and disruptiveness explained additional variance above and beyond the general mental illness stigma scale (see Table 5).

First, stigma and concealability explained $27 \%$ of the variance in hireability, $F(2$, $72)=13.16, p<.001$, however although stigma was significant at step $1, \beta=-.51(\mathrm{SE}=$ $.10), p<.001$, concealability was not significant at step $2, \beta=.09(\mathrm{SE}=.10), n s$. Further, $\Delta R^{2}=.01$ and was not statistically significant, $F(1,72)=0.96, n s$, and thus was not in support of $H 4 b$.

Second, stigma and course explained $33 \%$ of the variance in hireability, $F(2,72)$ $=17.48, p<.001$, and steps 1 and 2 were statistically significant with the inclusion of stigma, $\beta=-.51(\mathrm{SE}=.10), p<.001$, and course, $\beta=-.27(\mathrm{SE}=.10), p<.01$, respectively. Further, $\Delta R^{2}=.07$ and was statistically significant, $F(1,72)=7.38, p<.01$, thus supporting $H 4 b$.

Third, stigma and disruptiveness explained $40 \%$ of the variance in hireability, $F(2,72)=26.09, p<.001$, and steps 1 and 2 were statistically significant with the 
inclusion of stigma, $\beta=-.51(\mathrm{SE}=.10), p<.001$, and disruptiveness, $\beta=-.54(\mathrm{SE}=.11)$, $p<.001$, respectively. Further, $\Delta R^{2}=.14$ and was statistically significant, $F(1,72)=$ $16.62, p<.001$, thus supporting $H 4 b$.

Fourth, stigma and aesthetics explained $28 \%$ of the variance in hireability, $F(2$, $72)=14.29, p<.001$, however although stigma was significant at step $1, \beta=-.51(\mathrm{SE}=$ $.10), p<.001$, aesthetics was not significant at step $2, \beta=.19(\mathrm{SE}=.12), n s$. Further, $\Delta R^{2}$ $=.03$ and was not statistically significant, $F(1,72)=2.64, n s$, and thus was not in support of $H 4 b$.

Fifth, stigma and origin explained $27 \%$ of the variance in hireability, $F(2,72)=$ $12.69, p<.001$, however although stigma was significant at step $1, \beta=-.51(\mathrm{SE}=.10), p$ $<.001$, origin was not significant at step $2, \beta=.17(\mathrm{SE}=.14), n s$. Further, $\Delta R^{2}=.02$ and was not statistically significant, $F(1,72)=1.48, n s$, and thus was not in support of $H 4 b$.

Sixth, stigma and peril explained $27 \%$ of the variance in hireability, $F(2,72)=$ $13.18, p<.001$, however although stigma was significant at step $1, \beta=-.51(\mathrm{SE}=.10), p$ $<.001$, peril was not significant at step $2, \beta=-.15(\mathrm{SE}=.15), n s$. Further, $\Delta R^{2}=.01$ and was not statistically significant, $F(1,72)=.99, n s$, and thus was not in support of $H 4 b$.

To answer Research Question 1 (will there be differences in the stigma perceptions for individuals who are known to be diagnosed with depression $(R Q 1 a)$, an anxiety disorder $(R Q 1 b)$, substance use disorder $(R Q 1 c)$, or schizophrenia $(R Q 1 d)$ ?), I ran a MANOVA with the six stigma dimensions as dependent variables and the type of mental illness that the applicant was known to have as the independent variable. All post hoc tests were run with Bonferroni adjustments (Tabachnick \& Fidell, 2012). The 
omnibus MANOVA for the main effect of mental illness condition was not significant, Wilks's $\lambda=.91$, partial $\eta^{2}=.03$, and none of the univariate ANOVAs or post hoc tests for the W-MISS dimensions were significant (See Table 6). Thus, I found no statistically significant differences in stigma perceptions across mental illness conditions.

To answer Research Questions 2 and 3 (RQ2: will the relative importance of the W-MISS dimensions and a general measure of mental illness stigma on hireability differ for individuals who are known to be diagnosed with depression $(R Q 2 a)$, an anxiety disorder $(R Q 2 b)$, substance use disorder $(R Q 2 c)$, or schizophrenia $(R Q 2 d) ? ; R Q 3:$ Will the order of the relative importance of the W-MISS dimensions on hireability differ for individuals who are known to be diagnosed with depression $(R Q 3 a)$, an anxiety disorder $(R Q 3 b)$, substance use disorder $(R Q 3 c)$, or schizophrenia $(R Q 3 d)$ ?) I utilized relative importance analysis (Tonidandel \& LeBreton, 2011, 2015), which is of particular use to answer these research questions for a number of reasons. First, rather than beta weights, relative importance analysis provides relative weights for each predictor, which represent the proportion of total variance explained distributed across the predictors in the model (raw relative weight), and a relative weight value rescaled as a percentage of the predicted variance. Second, the analysis uses a bootstrapping approach $(10,000$ replications) to obtain standard errors and associated $95 \%$ confidence intervals for the relative weights. Third, the analysis provides $95 \%$ confidence intervals in reference to the difference between the relative weights (also via a bootstrapping approach with 10,000 replications), thus providing empirical tests of whether each predictor demonstrates differential predictive validity. 
Regarding the differences of the relative importance of the W-MISS dimensions and the general mental illness stigma scale for those who are known to be diagnosed with depression, disruptiveness was a significantly more important predictor of hireability compared to course, origin, and the general measure of stigma (as the confidence intervals did not overlap). The relative weights of all other predictors were not significantly different from one another $(R Q 2 a)$. For those who were known to be diagnosed with anxiety, no significant differences for the relative weights of the predictors were found $(R Q 2 b)$. For those who were diagnosed with substance use disorder, no significant differences for the relative weights of the predictors were found $(R Q 2 c)$. Finally, for those who were diagnosed with schizophrenia, no significant differences for the relative weights of the predictors were found $(R Q 2 d)$. Thus, although disruptiveness was found to be significantly more important than the general stigma measure, course, and origin for those known to be diagnosed with depression, for all other mental illness diagnoses no predictor was found to be significantly more or less important relative to one another (see Table 7).

Regarding the order of the relative importance of W-MISS predictors on hireability for those known to be diagnosed with depression, disruptiveness was most important, followed by concealability, aesthetics, peril, course, and origin, although as noted above only disruptiveness was significantly more important than course and origin $(R Q 3 a)$. For those who were known to be diagnosed with anxiety, disruptiveness was the most important predictor, followed by peril, aesthetics, origin, course, and concealability, although as noted above none of the relative weights were significantly different from 
one another $(R Q 3 b)$. For those who were known to be diagnosed with a substance use disorder, course was the most important predictor, followed by disruptiveness, origin, aesthetics, peril, and concealability, although as noted above none of the relative weights were significantly different from one another $(R Q 3 c)$. Finally, for those who were known to be diagnosed with schizophrenia, disruptiveness was the most important predictor, followed by concealability, peril, course, aesthetics, and origin $(R Q 3 d)$. Thus, although disruptiveness tends to be the most important predictor, the order of importance does differ across mental illness diagnoses (see Table 7). 


\section{Chapter 4: Discussion}

Mental illness in the workplace remains remarkably understudied. Despite being common (National Institute of Mental Health, n.d.) and protected under the Americans with Disabilities Act, disability discrimination related to mental illness remains high (i.e., with more formal charges than race, national origin, religion, color, or age; EEOC, 2019). A key first step to reducing discrimination due to mental illness status is reducing the prejudiced, stereotyping attitudes that contribute to the stigma (see Ajzen, 2012). To reduce the stigma surrounding mental illness at work, one must first be able to measure mental illness stigma, as it applies to the workplace. With theoretically based and empirically validated measurement tools, it is possible to better understand how the stigma surrounding mental illness impacts perceptions in the workplace-an understanding that can inform future efforts to reduce stigma and associated discrimination.

Across seven samples and 1030 participants, I developed and examined the utility of a multidimensional conceptualization of a workplace mental illness stigma scale. To this end, I drew upon Jones et al.'s (1984) conceptualization of stigma—which, although well cited, has never been formally measured with a validated measure in workplace contexts for any stigmatized attribute-in order to develop the six dimension Workplace Mental Illness Stigma Scale (the W-MISS). Additionally, I examined the new measure's predictive validity and incremental validity above and beyond the dominantly used mental illness stigma scale (Griffiths et al., 2004). The W-MISS has important 
implications for many scholars and practitioners who will no longer be required to rely upon less nuanced measures.

\section{Findings}

Using Hinkin's (1998) deductive scale development approach, I developed the WMISS based off Jones et al.’s (1984) six stigma dimensions. In particular, SMEs developed a pool of items that were evaluated for content validity, further trimmed in a series of exploratory factor analyses, and then examined for factor structure by using confirmatory factor analysis. In support of Hypothesis 1, the six-factor model fit better than any examined five-factor $(H 1 a)$, four-factor $(H 1 b)$, three-factor $(H 1 c)$, two-factor $(H 1 d)$, or one-factor model $(H l e)$. This is theoretically important as these findings provide strong support for Jones et al.'s (1984) conceptualization of stigma. Further, this model supports Stone and Colella's (2001) seminal theoretical work which drew upon Jones et al.'s (1984) stigma dimensions to consider workplace experiences of those with a disability. As all the items were written specifically for workplace stigma perceptions of those with a mental illness status, it may have been possible that some of the factors may have collapsed or that mental illness stigma was perceived as a unitary construct.

However, these empirical findings support the theoretically-based multidimensional model of workplace mental illness stigma perceptions.

After establishing the quality of the items and confirming the W-MISS's factor structure, I examined the convergent and discriminant validity of the W-MISS with multiple similar and disparate constructs. Overall, the W-MISS demonstrated convergent and discriminant validity, as predicted, with a few exceptions. Specifically, 
concealability did not significantly correlate with RWA or SDO and disruptiveness did not correlate with RWA. Further, all six of the W-MISS' dimensions significantly correlated with self-esteem. Below, I discuss convergent and discriminant validity evidence in more depth (Hypotheses 2 and 3).

To test Hypothesis 2 and establish convergent validity, I examined the correlations between the W-MISS dimensions and a general measure of mental illness stigma, right-wing authoritarianism, and social dominance orientation. I found that the W-MISS dimensions were significantly correlated with the general measure of mental illness stigma (supporting $\mathrm{H} 2 a$ ). However, only course, aesthetics, origin, and peril were significantly correlated with right-wing authoritarianism (partial support of $H 2 b$ ); course, disruptiveness, aesthetics, origin, and peril were significantly correlated with social dominance orientation (partial support of $H 2 c$ ).

Although the dimensions generally demonstrated convergent validity, concealability only demonstrated significant correlations with the general mental illness stigma measure. Further, concealability was only significantly correlated with peril, but not any of the other W-MISS factors. This is interesting as concealability is one of the most commonly examined of the stigma dimensions in the organizational science literature (see Jones and King, 2014 for a review), although it is generally discussed as a trait of a stigma characteristic (i.e., a stigma characteristic is either concealable or it is not) rather than as a stigma perception (e.g., Clair, Beatty, \& Maclean, 2005; Ragins, 2008). Upon further examination, participants were found to use the full scale and responses were neither skewed nor kurtotic $(M=4.36, S D=1.51$, skewness $=-0.33$, 
kurtosis $=-0.88$ ). This suggests that although participants did differentially perceive how concealable one's mental illness may be, these perceptions were largely unrelated to the other stigma dimensions and to other theoretically convergent measures (e.g., right wing authoritarianism, social dominance orientation).

One explanation may be that there are potentially both positive and negative outcomes associated with the perception of whether an individual can conceal their stigmatized identity. In fact, the literature that has considered workplace disclosure of mental illness has found both costs and benefits to disclosure on workplace relationships among supervisors and coworkers (for a review, see Jones, 2011). Jones et al. (1984) argue that the concealability of one's stigma attribute may result in others fearing such individuals, particularly with mental illness status (as it may be difficult to predict behavioral outcomes). My finding that concealability was only significantly correlated with peril supports such an argument. Further, if it is difficult to perceive whether an individual has a mental illness, others may question the legitimacy of the identity, which may also be related to negative workplace outcomes, such as difficulty in obtaining accommodations (Krupa et al., 2009). Alternatively, if mental illnesses are thought of as concealable in workplace contexts, perceivers may feel that this is an advantage for those with a mental illness. As those with readily apparent stigmas are often treated poorly (Gouvier et al., 1991; Kleck, 1968), the ability to conceal one's stigmatized identity may be thought of as a skill that could be leveraged to avoid negative interpersonal outcomes. For example, managers may wish that those with a mental illness not disclose to coworkers or clients and may further believe that if others cannot perceive an individual's 
mental illness status then there may likely be fewer workplace conflicts due to one's mental illness status. If this is the case, managers may be less likely to discriminate against an individual due to their mental illness status in a selection context, but then may be less likely to support those individuals once on the job.

To examine Hypothesis 3 and establish discriminant validity, I examined the correlations between the W-MISS dimensions and measures of self-esteem, social desirability, and social support. I found that self-esteem was negatively correlated with all six stigma dimensions ( $H 3 a$ unsupported), although the correlations were smallmedium effects $(r=-.21-.34)$. Additionally, I found that the W-MISS dimensions were not correlated with social desirability ( $H 3 b$ supported) and social support ( $H 3 c$ supported). It is interesting that self-esteem was negatively correlated with mental illness stigma perceptions as this suggests that one's view of their own self-esteem may be related to their stigma perceptions of mental illness.

Although social identity researchers have examined the role that self-esteem may play on intergroup discrimination (i.e., whether self-esteem is a motivator for, and/or an outcome of, intergroup discrimination; Abrams \& Hogg, 1988), findings have been mixed (for a review, see Rubin \& Hewstone, 1998). Researchers have also examined the relationship between self-esteem and ingroup bias, with meta-analytic evidence suggesting that higher self-esteem may be related to more ingroup bias (Aberson, Healy, \& Romero, 2000). Additionally, although only tangentially related, researchers have found a link between self-esteem and increased bullying behaviors (e.g., O’Moore \& Kirkham, 2001). However, my findings are counter to prior work examining the 
relationship between stigma and self-esteem, although each of these aforementioned studies examined stigma perceptions against trans people (e.g., Hill \& Willoughby, 2005; Walch et al., 2012).

Further, the finding that social desirability was not significantly related to any of the dimensions of the W-MISS demonstrates that individuals were likely open in terms of how they responded to these questions. This finding is in line with prior work that has demonstrated that sampling strategies which allow for relatively high levels of anonymity may result in more honest responses (Richman, Kiesler, Weisband, \& Drasgow, 1999).

After establishing the convergent and discriminant validity of the W-MISS dimensions, I examined the predictive validity of the W-MISS with a selection vignette study. Particularly, participants were directed to a resume in which the ostensible job candidate had a gap in employment and disclosed that the gap was due to receiving treatment for either a) a mental illness, b) depression, c) anxiety, d) substance use disorder, or e) schizophrenia. Then participants provided hireability ratings and responded to the W-MISS dimensions. Regarding mental illness, I found that concealability, course, disruptiveness, origin and peril were significantly associated with hireability, but aesthetics was only marginally associated with hireability (partial support of $H 4 a$; hireability ratings associated with depression, anxiety, substance disorders, and schizophrenia are discussed below, within the context of research questions). Overall, this is in support of my hypothesis and demonstrates the potential importance of each of the stigma dimensions. This finding bolsters Jones et al.' (1984) conceptualization of stigma and supports Stone and Colella's (1998) theoretical model exploring the treatment 
of individuals with a disability in workplace contexts, which provides a much-needed theoretical orientation to the workplace mental illness literature considering stigma.

In terms of what this finding might mean for individuals with mental illnesses, there are important implications for the identity management literature. For example, providing individuating information or engaging in identity claiming have both been found to result in positive outcomes for workers with stigmatized identities, including those with a disability (Lyons et al., 2018; Singletary \& Hebl, 2009). This finding suggests that individuals with a mental illness might benefit from highlighting positive and counter-stereotypic information across any number of Jones et al.'s (1984) stigma dimensions. This finding also has important implications for workplace trainings focused on reducing stigma perceptions of those with a mental illness and suggests that these trainings should focus on each of these dimensions, rather than only discussing stigma, in general.

Additionally, regarding incremental validity, only course and disruptiveness explained additional variance above and beyond the general measure of mental illness stigma (partial support of $H 4 b$ ). Although the W-MISS did not consistently demonstrate incremental validity above the general measure of mental illness stigma, the general measure already demonstrated a relatively strong relation with hireability $\left(R^{2}=.16\right)$, and it is meaningful that any of the dimensions explained additional variance above and beyond this measure. One reason the general measure might demonstrate a strong relationship with hireability perceptions is that it contains items across the stigma domain, including items specifically referencing selection (including an item on 
employing an individual with a mental illness and an item on selecting a political candidate with a mental illness; Griffiths et al., 2004), thus it is unsurprising that such a measure would correlate with a hireability inventory. The W-MISS may nevertheless be a more useful measure in workplace contexts as it is more face valid (only referencing the workplace context), is multidimensional, and is based in strong theory. Thus, the WMISS may allow researchers to take a more nuanced look at exactly how stigma perceptions are impacting attitudinal and behavioral outcomes, which is extremely important considering the high number of adults in the US with a mental illness status (Substance Abuse and Mental Health Services Administration, 2018).

Research questions. Finally, I examined a series of research questions. First, I asked if there would be differences in stigma perceptions on the W-MISS dimensions depending on the type of mental illness disclosed in the resume (i.e., depression, anxiety, substance use disorder, schizophrenia). Interestingly, no differences were found for any of the dimension across mental illness type $(R Q 1)$. This is useful as it may provide initial evidence that workplace stigma perceptions of mental illness may not dramatically differ across mental illness type. If this is the case, such a measure may readily be adapted to any number of mental illnesses and has important theoretical and practical implications for use. In particular, this measure could readily be adapted for use to examine stigma toward any number of mental illnesses, either by changing the referent group in the directions or by actually replacing the term "mental illness" with the particular mental illness of interest (e.g., depression, anxiety). Also, this finding suggests that although mental illness stigma is multidimensional, it may function similarly across different types 
of mental illnesses in the workplace (i.e., levels of stigma across the dimensions may not differ vastly depending upon the type of mental illness).

Second, I asked if the relative importance of the W-MISS dimensions and a general measure of mental illness stigma on hireability differ for those known to be diagnosed with depression, anxiety, substance use disorder, or schizophrenia. Regarding depression, disruptiveness was relatively more important compared to course, origin, and the general measure of stigma $(R Q 2 a)$, and no differences in the relative importance of the predictors was found for anxiety $(R Q 2 b)$, substance use disorder $(R Q 2 c)$, and schizophrenia $(R Q 2 d)$. Again, the lack of differences found suggest that each of these dimensions are similarly important for predicting discriminatory workplace behaviors, no matter the type of mental illness being examined. This finding further supports the general usefulness and potential for large-scale use of this measure when examining workplace mental illness stigma, and for comprehensively considering each of Jones et al.'s (1984) dimensions in workplace mental-illness stigma interventions.

Third, I asked if the order of relative importance would change depending on type of mental illness. For depression, disruptiveness was most important, followed by concealability, aesthetics, peril, course, and origin (although disruptiveness was only significantly more important than course and origin; $R Q 3 a$ ). For anxiety, disruptiveness was most important, followed by peril, aesthetics, origin, course, and concealability, although none were significantly different from each other $(R Q 3 b)$. Regarding substance use disorder, course was the most important, followed by disruptiveness, origin, aesthetics, peril, and concealability, although none of these predictors were significantly 
different from one another $(R Q 3 c)$. Regarding schizophrenia, disruptiveness was most important, followed by concealability, peril, course, aesthetics, and origin $(R Q 3 d)$. These findings suggest that, overall, disruptiveness tends to be the most important predictor, but that the order of importance may differ depending on the type of mental illness.

These findings may be interpreted in several ways. First, as the relative importance of the predictors were generally not significantly different from one another, it may be possible that the predictors are similarly important for different mental illness types. However, interpreting the raw values from most to least important also provides potential insight into the relationship between stigma and specific mental illnesses. For example, for depression, anxiety, and schizophrenia, disruptiveness was the strongest predictor, which demonstrates that across multiple mental illness types, the perception that those with a mental illness cannot communicate with or interact with others effectively at work is highly related to hireability perceptions. This makes sense as, oftentimes, these are required workplace behaviors.

For substance use disorder, however, course (e.g., employees with a mental illness cannot recover) was the most important predictor, followed by disruptiveness. For substance use disorder, a potential employer would likely be very hesitant to hire an individual who they know to have used substances and who they believe cannot recover. This has important implications for perceptions of the course of the stigma attribute, as the perception of chronicity (e.g., that the individual is unlikely to be cured or recover) may be more important for specific types of mental illnesses (e.g., substance use) compared to others (e.g., depression), as some may be thought of as more manageable 
and less risky in workplace contexts. Although the overall use of comprehensive employment drug testing may be decreasing, many workplaces still adopt a zero tolerance policy and remain concerned about the legal risk associated with workers using substances (for a recent news article discussing the subject, see Roosevelt, 2019), even when not diagnosed with substance use disorder.

\section{Theoretical Implications}

Overall, the results of this study have several theoretical implications. Disability continues to be an understudied area of organizational science, with mental illness status representing one of the least studied disabilities. Further, although there has been some theoretical work completed in the organizational disability literature (Colella, 2001; Stone \& Colella, 1996), much of the organizational mental illness work has been largely atheoretical and fragmented across disciplines (cf. Dimoff \& Kelloway, 2016; Follmer \& Jones, 2018). Indeed, even the work done within organizational science continues to be siloed (for example, though Follmer and Jones' (2018) interdisciplinary review includes interventions including stigma reduction programs, work by Dimoff and Colleagues is not included).

Regarding the stigma surrounding mental illness status, other theoretical models may readily be adopted. For example, as mental illness status is relatively concealable, identity management theories (e.g., Clair et al., 2005; Fiske \& Neuberg, 1990; Ragins, 2008) are particularly appropriate to draw upon. Further, as mental illness status is not monolithic, it was thought that the type of mental illness status may be an important feature to examine. This is particularly the case in the organizational literature, as the 
importance of the particular mental illness being examined is often not considered (typically only one type of mental illness is explored without strong theoretical discussions of the impact of the attributes of that mental illness), or "mental illness", in general, is explored (without consideration of what sort of exemplar mental illness is being drawn upon by participants). However, my findings demonstrated that there were not that many differences in terms of the W-MISS' dimensions' relations to hireability. One potential explanation for these lack of differences is that people may not have a nuanced view of mental illnesses and rather draw upon more global assessments. This notion is further bolstered by the lack of significant findings across mental illness types regarding mean scores on the dimensions $(R Q 1)$ and the relative importance (and order of importance) of the dimensions in comparison to the general mental illness stigma measure across mental illness types $(R Q 2 \& R Q 3)$. However, more work needs to be done to explore such a possibility. Overall, researchers should continue to consider individual mental illnesses while applying theoretical models focusing on disability or mental illness, in general, to examine their replicability and generalizability across mental illness types.

Additionally, many of the aforementioned theoretical papers draw upon portions of Jones et al.'s (1984) conceptualization of stigma, except for Stone and Colella's (1996) seminal theoretical work on disability stigma (including mental illness), which comprehensively considered all six of Jones et al.'s (1984) stigma dimensions. However, until this point, the measurement of these factors has been lacking, which has important implications when considering the empirical examination of the importance of these 
dimensions. This measure development and validation represents the first comprehensive attempt (to my knowledge) of such a feat in a workplace domain across any type of stigmatized identity. Furthermore, as these dimensions were suggested to map onto stigma attributes, in general, the W-MISS could have far-reaching implications, as it may be readily adaptable to other types of stigmatized identities. Therefore, the W-MISS could be quite impactful in setting the stage for researchers to take a more nuanced measurement-based view of stigma perceptions across many different stigmatized identities in workplace contexts.

\section{Practical Implications}

This study also has several practical implications. As mental illness status is an extremely common stigmatized identity that affects millions of Americans every single year (Substance Abuse and Mental Health Services Administration, 2018), the likelihood of employing an individual with a mental illness status is extremely high. Thus, understanding mental illness status, along with appropriate accommodations and interventions, should be of interest to organizational leaders and members. The W-MISS could help to achieve such goals in several ways. For example, the W-MISS could represent a useful tool for organizational leaders to use as part of field surveys to gain a "pulse" on managerial and employee perceptions regarding mental illness stigma.

Results of such surveys could lead to recommendations for targeted intervention work or as part of a health and wellbeing needs assessment.

Additionally, the W-MISS could be used to evaluate the effectiveness of mental health awareness training for managers and employees - a rapidly growing area of 
research that is currently dependent on limited measures of mental illness stigma (Dimoff et al., 2016; Ellis, Casey, \& Krauss, 2017; Kitchener \& Jorm, 2004; Oakie, Smith, Dimoff, \& Kelloway, 2018). Without better measures to evaluate intervention effectiveness, practitioners risk evaluating programs ineffectively and inaccurately. As a result, organizations could risk investing in programs that do not work. Or worse, they could be led to believe that the training programs do not reduce stigma — not because they actually fail to reduce stigma, but because the stigma measures are poorly designed for a workplace context in terms of reliability and validity that they fail to capture the significant change.

\section{Limitations and Future Directions}

As with any study, this dissertation has several potential limitations. First, the content adequacy, exploratory factor analysis, confirmatory factor analysis, convergent and discriminant validity, and predictive validity samples are collected among one pool of participants: those who are workers on Amazon's MTurk. Although this may be considered a limitation by some, continued emergent work has discussed the potential validity and usefulness of this MTurk as a subject pool (e.g., Buhrmester et al., 2011, 2018; Smith et al., 2015), and recent meta-analytic evidence has demonstrated that online panel data, including MTurk is of similar quality and provides similar results as organizational samples (Walter et al., 2018). Further, responses from MTurkers have been found to demonstrate measurement invariance with workplace samples on popular scales when collected in the US (Feitosa et al., 2015). Additionally, due to the sensitive nature of the constructs that I examined (mental illness stigma, social dominance 
orientation, right-wing authoritarianism), the relative anonymity afforded to MTurkers may have resulted in increased comfort to provide more honest responses (Richman, et al., 1999). For example, the full range of many of the scales were used, including on the stigma dimensions, the general measure of mental illness stigma, social dominance orientation and right-wing authoritarianism. Notably, although general stigma and social dominance orientation were negatively skewed, right wing authoritarianism demonstrated a relatively normal curve.

Second, the predictive validity assessment of the W-MISS relied upon a crosssectional design (i.e., assessing both the predictor variables and outcomes variables in the same survey), obfuscating directionality. This is problematic as the potential for common method bias (Podsakoff, MacKenzie, Lee, \& Podsakoff, 2003) and priming were increased. Despite the limitation to this design, it is possible that hireability ratings, regardless of data collection time point, would be predicted by stigma. For instance, Ajzen (2012) argues that behavioral outcomes and behavioral intentions are predicted by cognitive or attitudinal responses. Thus, this design may act as an early first step in examining the predictive validity of W-MISS. Future studies should seek to collect attitudinal and behavioral data at two separate time points to help alleviate this limitation.

Future work should also seek to continue validation of the W-MISS and its useful in organizational research. In particular, the predictive validity findings should be triangulated with experimental design and/or longitudinal field studies and interventions. Additionally, given the similar importance of each of the dimensions for hireability, this work suggests that practitioners may be well served to discuss mental illness stigma in 
terms of each of these dimensions. For example, this theoretical framework could provide guidance on future iterations of workplace mental illness awareness training. In particular, Dimoff, Kelloway, and Burnstein's (2016) MHAT's first module provides knowledge about mental illness and mental illness stigma to trainees. This module could incorporate additional knowledge about mental illness stigma that more comprehensively covers the content domain (in terms of Jones et al.'s (1984) multidimensional conceptualization of stigma). Further, as Jones et al. (1984) theoretically developed their framework to consider the potential for negative attitudinal and behavioral outcomes for any number of stigmatized characteristics, this model (and resulting scale) may generalize to other stigmatized characteristics with relatively minimal adaptation-future work should consider this possibility. Evaluating the adaptability of the W-MISS is of particular use, as this dissertation represents the first attempt to validate a scale of workplace stigma for any stigma attribute within Jones et al.'s (1984) theoretical framework.

\section{Conclusion}

This scale development and validation study represents a thorough exploration of an understudied stigmatized identity in organizational science —-mental illness status. Although protected under the Americans with Disabilities Act, people with mental illnesses risk facing high levels of stigma and discrimination at work. By exploring more of the stigma content domain in reference to mental illness status, organizational researchers and practitioners can better understand the challenges faced by individuals with a mental illness status, can develop more effective workplace interventions, and can 
hope to improve workplace conditions for individuals with a mental illness status. The W-MISS has the potential to contribute to this growing body of literature on the relationship between mental illness, stigma, and the workplace. 
Tables 
Table 1

Study Design

\begin{tabular}{ll}
\hline Phase & Purpose \\
\hline Phase 1: Item Generation & $\begin{array}{l}\text { Develop initial pool of items based on Jones } \\
\text { et al.'s (1984) dimensions }\end{array}$
\end{tabular}

Phase 2: Content Validation / Item Reduction

Content Adequacy

Item Reduction

Phase 3: Exploratory Factor Analysis

Phase 4: Confirmatory Factor Analysis

Phase 5: Convergent / Discriminant Validity

Phase 6: Predictive Validity
Determine appropriateness of items with an item sorting task in which participants identified which of Jones et al.'s (1984) dimensions best represented each item Evaluate clarity and relevancy of remaining items

Refine and reduce number of items ensuring strong loadings on their hypothesized factor with minimal cross-loadings

Confirming factor structure of final pool of items

Establishing nomological network of developed factors with theoretically similar and distinct constructs

Evaluate predictive and incremental power of developed factors 
Table 2

Summary of Exploratory Factor Analysis Results

\begin{tabular}{|c|c|c|c|c|c|c|c|}
\hline Factor & Item wording & 1. & 2. & 3. & 4. & 5. & 6. \\
\hline \multirow[t]{4}{*}{ 1. Concealability } & $\begin{array}{l}\text { 1. At work, it tends to be difficult to tell when } \\
\text { someone has a mental illness. }\end{array}$ & -.06 & .08 & .08 & .88 & -.07 & .00 \\
\hline & $\begin{array}{l}\text { 2. Employees with mental illnesses can hide their } \\
\text { symptoms from others in the workplace. }\end{array}$ & .00 & -.06 & -.03 & .82 & .12 & -.03 \\
\hline & $\begin{array}{l}\text { 3. Unless an employee discloses that they have a } \\
\text { mental illness, it is unlikely other people at work } \\
\text { would know. }\end{array}$ & -.01 & .04 & .05 & .96 & -.07 & .00 \\
\hline & $\begin{array}{l}\text { 4. Symptoms of mental illnesses tend to be } \\
\text { concealable in the workplace. }\end{array}$ & .09 & -.06 & -.11 & .79 & .03 & .04 \\
\hline \multirow[t]{4}{*}{ 2. Course } & $\begin{array}{l}\text { 1. Employees with mental illnesses usually have these } \\
\text { problems for life. }\end{array}$ & -.07 & .79 & .03 & .08 & .07 & -.08 \\
\hline & 2. Employees with mental illnesses rarely recover. & .09 & .78 & .03 & -.05 & -.03 & .02 \\
\hline & $\begin{array}{l}\text { 3. Employees with mental illnesses are unlikely to be } \\
\text { cured. }\end{array}$ & -.01 & .91 & -.05 & -.03 & .04 & .03 \\
\hline & $\begin{array}{l}\text { 4. Employees with mental illnesses tend to have a } \\
\text { chronic condition that cannot be helped. }\end{array}$ & .04 & .81 & .02 & -.01 & -.03 & .06 \\
\hline \multirow[t]{4}{*}{ 3. Disruptiveness } & $\begin{array}{l}\text { 1. Employees with mental illnesses tend to have } \\
\text { difficulty communicating well with others at work. }\end{array}$ & .14 & .00 & .78 & -.03 & .06 & -.03 \\
\hline & $\begin{array}{l}\text { 2. Employees with mental illnesses can have a } \\
\text { difficult time interacting with others at work. }\end{array}$ & -.09 & .11 & .88 & .02 & -.05 & -.04 \\
\hline & $\begin{array}{l}\text { 3. Employees with mental illnesses tend to have a } \\
\text { difficult time being good team players. }\end{array}$ & -.03 & -.06 & .93 & .00 & .04 & .04 \\
\hline & $\begin{array}{l}\text { 4. Employees with mental illnesses tend to be } \\
\text { exhausting to interact with at work. }\end{array}$ & .07 & -.03 & .76 & -.02 & .06 & .05 \\
\hline \multirow[t]{4}{*}{ 4. Aesthetics } & $\begin{array}{l}\text { 1. Employees with mental illnesses tend to have poor } \\
\text { hygiene at work. }\end{array}$ & .10 & .01 & .02 & -.03 & .04 & .83 \\
\hline & 2. Employees with mental illnesses tend to smell bad. & .16 & -.01 & -.03 & .02 & -.02 & .86 \\
\hline & $\begin{array}{l}\text { 3. Employees with mental illnesses tend to look } \\
\text { disheveled. }\end{array}$ & .07 & .02 & .04 & .00 & .03 & .84 \\
\hline & $\begin{array}{l}\text { 4. Employees with mental illnesses tend to look } \\
\text { unkempt. }\end{array}$ & .16 & .01 & .01 & .02 & -.01 & .81 \\
\hline \multirow[t]{4}{*}{ 5. Origin } & $\begin{array}{l}\text { 1. Employees with mental illnesses tend to be } \\
\text { responsible for their condition. }\end{array}$ & .93 & .01 & -.01 & .00 & .01 & .02 \\
\hline & $\begin{array}{l}\text { 2. Employees with mental illnesses often only have } \\
\text { themselves to blame for their condition. }\end{array}$ & .97 & -.01 & -.02 & .00 & .06 & -.04 \\
\hline & $\begin{array}{l}\text { 3. Employees who have mental illnesses likely could } \\
\text { have prevented them. }\end{array}$ & .92 & .05 & -.03 & .01 & .05 & -.02 \\
\hline & $\begin{array}{l}\text { 4. Mental illnesses tend to only affect employees who } \\
\text { are weak. }\end{array}$ & .91 & -.03 & .07 & .01 & -.11 & .09 \\
\hline \multirow[t]{4}{*}{ 6. Peril } & $\begin{array}{l}\text { 1. Employees with mental illnesses can be violent at } \\
\text { work. }\end{array}$ & -.06 & .05 & .00 & .01 & .89 & -.01 \\
\hline & $\begin{array}{l}\text { 2. Employees with mental illnesses are likely to hurt } \\
\text { someone else at work. }\end{array}$ & .11 & .00 & .03 & -.01 & .85 & .01 \\
\hline & $\begin{array}{l}\text { 3. Employees with mental illnesses are likely to pose } \\
\text { a threat to public safety. }\end{array}$ & .05 & -.01 & .03 & .00 & .89 & .04 \\
\hline & $\begin{array}{l}\text { 4. Employees with a mental illness are likely a danger } \\
\text { to themselves. }\end{array}$ & -.01 & .04 & .10 & .03 & .73 & .01 \\
\hline
\end{tabular}

Note. Factor loadings over .40 appear in boldface 
Table 3

Confirmatory Factor Analysis Model Comparisons

\begin{tabular}{|c|c|c|c|c|c|c|c|c|c|}
\hline Model & & & $\chi^{2}$ & $\mathrm{df}$ & $\Delta \chi^{2}$ & CFI & TLI & RMSEA & SRMR \\
\hline 6 Factors & A1 & $1,2,3,4,5,6$ & 457.20 & 237 & & .96 & .95 & .07 & .05 \\
\hline \multirow[t]{15}{*}{5 Factors } & $\mathrm{B} 1$ & $1,2,3,4,5+6$ & 908.94 & 242 & $451.74 * *$ & .87 & .85 & .12 & .09 \\
\hline & B2 & $1,2,3,5,4+6$ & 901.54 & 242 & $444.34 * *$ & .87 & .86 & .12 & .08 \\
\hline & B3 & $1,2,3,6,4+5$ & 998.48 & 242 & $541.28^{* *}$ & .86 & .84 & .13 & .07 \\
\hline & B4 & $1,2,4,5,3+6$ & 619.97 & 242 & $162.77 * *$ & .93 & .92 & .09 & .05 \\
\hline & B5 & $1,2,4,6,3+5$ & 914.36 & 242 & $457.16^{* *}$ & .87 & .85 & .12 & .10 \\
\hline & B6 & $1,2,5,6,3+4$ & 858.94 & 242 & $401.74 * *$ & .88 & .87 & .11 & .09 \\
\hline & B7 & $1,3,4,5,2+6$ & 757.32 & 242 & $300.12 * *$ & .90 & .89 & .10 & .06 \\
\hline & B8 & $1,3,4,6,2+5$ & 883.99 & 242 & $426.79 * *$ & .88 & .86 & .12 & .10 \\
\hline & B9 & $1,3,5,6,2+4$ & 865.35 & 242 & $408.15^{* *}$ & .88 & .86 & .11 & .10 \\
\hline & B10 & $1,4,5,6,2+3$ & 678.46 & 242 & $221.26^{* *}$ & .92 & .90 & .10 & .06 \\
\hline & B11 & $2,3,4,5,1+6$ & 1013.52 & 242 & $556.32 * *$ & .85 & .83 & .13 & .11 \\
\hline & B12 & $2,3,4,6,1+5$ & 994.67 & 242 & $537.47 * *$ & .86 & .84 & .13 & .11 \\
\hline & B13 & $2,3,5,6,1+4$ & 1016.34 & 242 & $559.14 * *$ & .85 & .83 & .13 & .12 \\
\hline & B14 & $2,4,5,6,1+3$ & 1016.64 & 242 & $559.44 * *$ & .85 & .83 & .13 & .12 \\
\hline & B15 & $3,4,5,6,1+2$ & 1010.93 & 242 & $553.73 * *$ & .85 & .83 & .13 & .11 \\
\hline \multirow[t]{20}{*}{4 Factors } & $\mathrm{C} 1$ & $1,2,3,4+5+6$ & 1376.39 & 246 & $919.19 * *$ & .78 & .76 & .15 & .08 \\
\hline & $\mathrm{C} 2$ & $1,2,4,3+5+6$ & 1247.39 & 246 & $790.19 * *$ & .81 & .78 & .14 & .08 \\
\hline & $\mathrm{C} 3$ & $1,2,5,3+4+6$ & 1147.37 & 246 & $690.17 * *$ & .83 & .81 & .14 & .07 \\
\hline & $\mathrm{C} 4$ & $1,2,6,3+4+5$ & 1389.19 & 246 & $931.99 * *$ & .78 & .75 & .15 & .09 \\
\hline & $\mathrm{C} 5$ & $1,3,4,2+5+6$ & 1300.55 & 246 & $843.35^{* *}$ & .80 & .77 & .15 & .10 \\
\hline & C6 & $1,3,5,2+4+6$ & 1255.96 & 246 & $798.76^{* *}$ & .81 & .78 & .14 & .09 \\
\hline & $\mathrm{C} 7$ & $1,3,6,2+4+5$ & 1397.82 & 246 & $940.62 * *$ & .78 & .75 & .15 & .10 \\
\hline & $\mathrm{C} 8$ & $1,4,5,2+3+6$ & 867.85 & 246 & $410.65^{* *}$ & .88 & .87 & .11 & .06 \\
\hline & $\mathrm{C} 9$ & $1,4,6,2+3+5$ & 1284.68 & 246 & $827.48 * *$ & .80 & .78 & .15 & .11 \\
\hline & $\mathrm{C} 10$ & $1,5,6,2+3+4$ & 1202.25 & 246 & $745.05^{* *}$ & .82 & .79 & .14 & .10 \\
\hline & $\mathrm{C} 11$ & $2,3,4,1+5+6$ & 1449.34 & 246 & $992.14 * *$ & .77 & .74 & .16 & .13 \\
\hline & $\mathrm{C} 12$ & $2,3,5,1+4+6$ & 1459.69 & 246 & $1002.49 * *$ & .77 & .74 & .16 & .13 \\
\hline & $\mathrm{C} 13$ & $2,3,6,1+4+5$ & 1532.24 & 246 & $1075.04 * *$ & .75 & .72 & .16 & .12 \\
\hline & C14 & $2,4,5,1+3+6$ & 1176.34 & 246 & $719.14^{* *}$ & .82 & .80 & .14 & .12 \\
\hline & $\mathrm{C} 15$ & $2,4,6,1+3+5$ & 1451.43 & 246 & $994.23 * *$ & .77 & .74 & .16 & .14 \\
\hline & C16 & $2,5,6,1+3+4$ & 2427.37 & 246 & $1970.17 * *$ & .58 & .53 & .21 & .37 \\
\hline & $\mathrm{C} 17$ & $3,4,5,1+2+6$ & 1311.70 & 246 & $854.50 * *$ & .80 & .77 & .15 & .12 \\
\hline & $\mathrm{C} 18$ & $3,4,6,1+2+5$ & 1420.56 & 246 & $963.36^{* *}$ & .78 & .75 & .16 & .14 \\
\hline & C19 & $3,5,6,1+2+4$ & 2247.90 & 246 & $1790.70 * *$ & .62 & .57 & .20 & .21 \\
\hline & $\mathrm{C} 20$ & $4,5,6,1+2+3$ & 1798.38 & 246 & $1341.18 * *$ & .70 & .67 & .18 & .32 \\
\hline 3 Factors & D1 & $1,2,3+4+5+6$ & 1649.69 & 249 & $1192.49 * *$ & .73 & .70 & .17 & .09 \\
\hline
\end{tabular}




\begin{tabular}{cccccccccc}
\hline Model & & & \multicolumn{1}{c}{$\chi^{2}$} & $\mathrm{df}$ & $\Delta \chi^{2}$ & CFI & TLI & RMSEA & SRMR \\
\hline & D2 & $1,3,2+4+5+6$ & 1729.36 & 249 & $1272.16^{* *}$ & .72 & .69 & .17 & .10 \\
& D3 & $1,4,2+3+5+6$ & 1529.64 & 249 & $1072.44^{* *}$ & .75 & .73 & .16 & .09 \\
& D4 & $1,5,2+3+4+6$ & 1419.97 & 249 & $962.77^{* *}$ & .78 & .75 & .15 & .08 \\
& D5 & $1,6,2+3+4+5$ & 1716.23 & 249 & $1259.03^{* *}$ & .72 & .69 & .17 & .10 \\
& D6 & $2,3,1+4+5+6$ & 1915.08 & 249 & $1457.88^{* *}$ & .68 & .65 & .18 & .13 \\
& D7 & $2,4,1+3+5+6$ & 1786.81 & 249 & $1329.61^{* *}$ & .71 & .67 & .18 & .13 \\
& D8 & $2,5,1+3+4+6$ & 1702.47 & 249 & $1245.27^{* *}$ & .72 & .69 & .17 & .12 \\
& D9 & $2,6,1+3+4+5$ & 1924.52 & 249 & $1467.32^{* *}$ & .68 & .64 & .18 & .13 \\
& D10 & $3,4,1+2+5+6$ & 1841.52 & 249 & $1384.32^{* *}$ & .69 & .66 & .18 & .15 \\
& D11 & $3,5,1+2+4+6$ & 1808.69 & 249 & $1351.49^{* *}$ & .70 & .67 & .18 & .13 \\
& D12 & $3,6,1+2+4+5$ & 1932.40 & 249 & $1475.20^{* *}$ & .68 & .64 & .18 & .14 \\
& D13 & $4,5,1+2+3+6$ & 1422.12 & 249 & $964.92^{* *}$ & .78 & .75 & .15 & .12 \\
& D14 & $4,6,1+2+3+5$ & 1822.43 & 249 & $1365.23^{* *}$ & .70 & .67 & .18 & .15 \\
& D15 & $5,6,1+2+3+4$ & 1756.99 & 249 & $1299.79^{* *}$ & .71 & .68 & .17 & .14 \\
2 Factors & E1 & $1+2+3+4+5,6$ & 2252.24 & 251 & $1795.04^{* *}$ & .62 & .58 & .20 & .14 \\
& E2 & $1+2+3+4+6,5$ & 1970.68 & 251 & $1513.48^{* *}$ & .67 & .64 & .19 & .13 \\
& E3 & $1+2+3+5+6,4$ & 2069.13 & 251 & $1611.93^{* *}$ & .65 & .62 & .19 & .13 \\
& E4 & $1+2+4+5+6,3$ & 2267.62 & 251 & $1810.42^{* *}$ & .61 & .57 & .20 & .14 \\
& E5 & $1+3+4+5+6,2$ & 2186.61 & 251 & $1729.41^{* *}$ & .63 & .59 & .20 & .13 \\
& E6 & $2+3+4+5+6,1$ & 1946.25 & 251 & $1489.05^{* *}$ & .68 & .64 & .18 & .10 \\
& F1 & $1+2+3+4+5+6$ & 2482.94 & 252 & $2025.74^{* *}$ & .57 & .53 & .21 & .14 \\
\hline
\end{tabular}

Note. ** $p<.01$ 


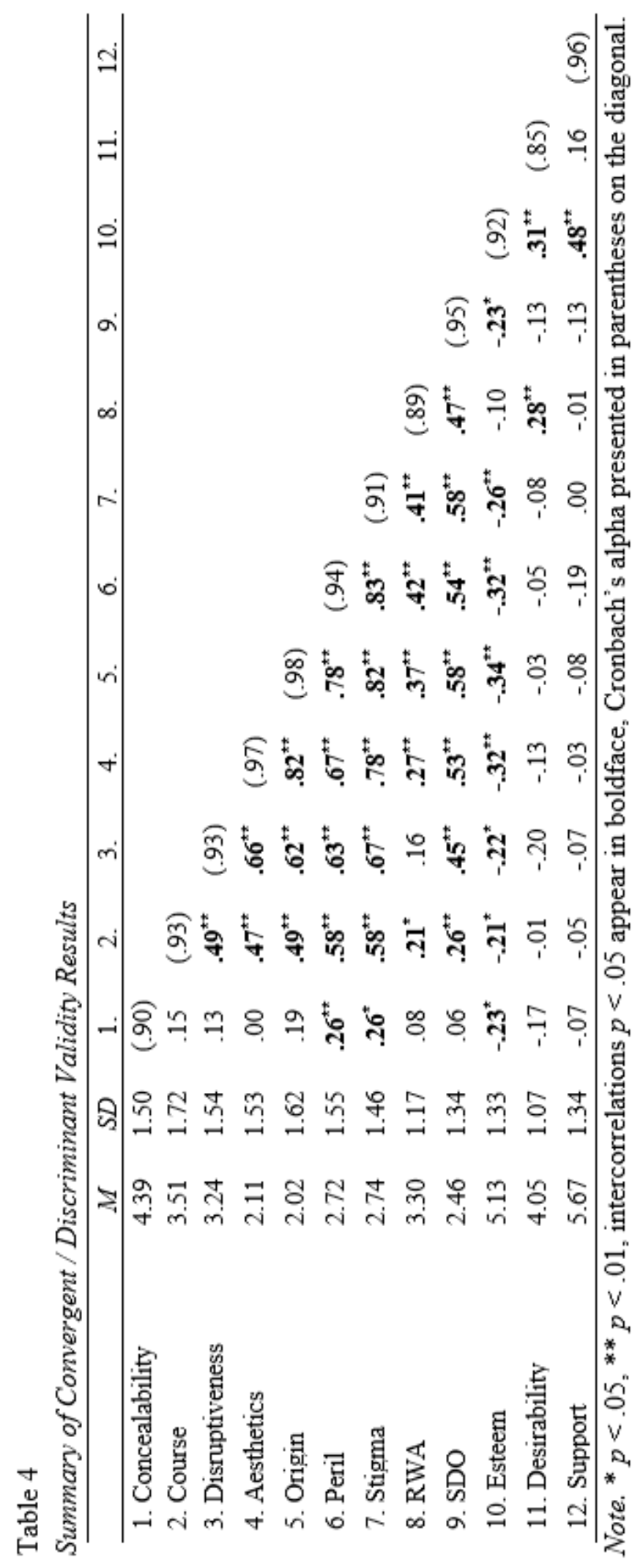




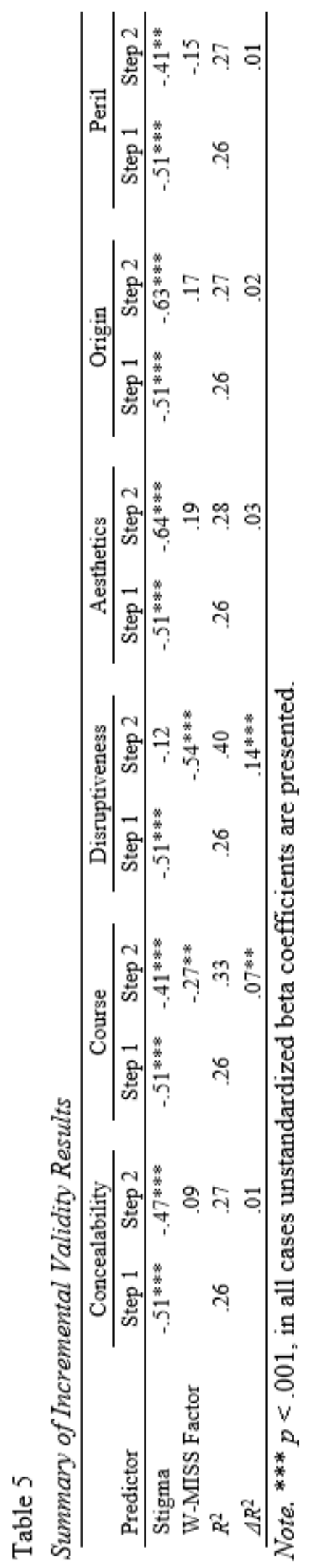


Table 6

Examination of mental illness types on outcomes

\begin{tabular}{lccccc}
\hline \multicolumn{7}{c}{ Multivariate test of significance } \\
\hline Test & $d f$ & error $d f$ & $F$ & $\eta^{2}$ & Wilks's $\lambda$ \\
Wilks' Lambda & 18 & 766.99 & 1.51 & .03 & 0.91 \\
& \multicolumn{7}{c}{ Univariate F-tests } \\
\hline \multicolumn{7}{c}{ Dependent Variable } & $d f$ & error df & $F$ & $\eta^{2}$ & \\
\hline Concealability & 3 & 276 & 0.67 & .01 & \\
Course & 3 & 276 & 1.97 & .02 & \\
Disruptiveness & 3 & 276 & 1.24 & .01 & \\
Aesthetics & 3 & 276 & 2.13 & .02 & \\
Origin & 3 & 276 & 0.62 & .01 & \\
Peril & 3 & 276 & 2.48 & .03 & \\
\hline
\end{tabular}




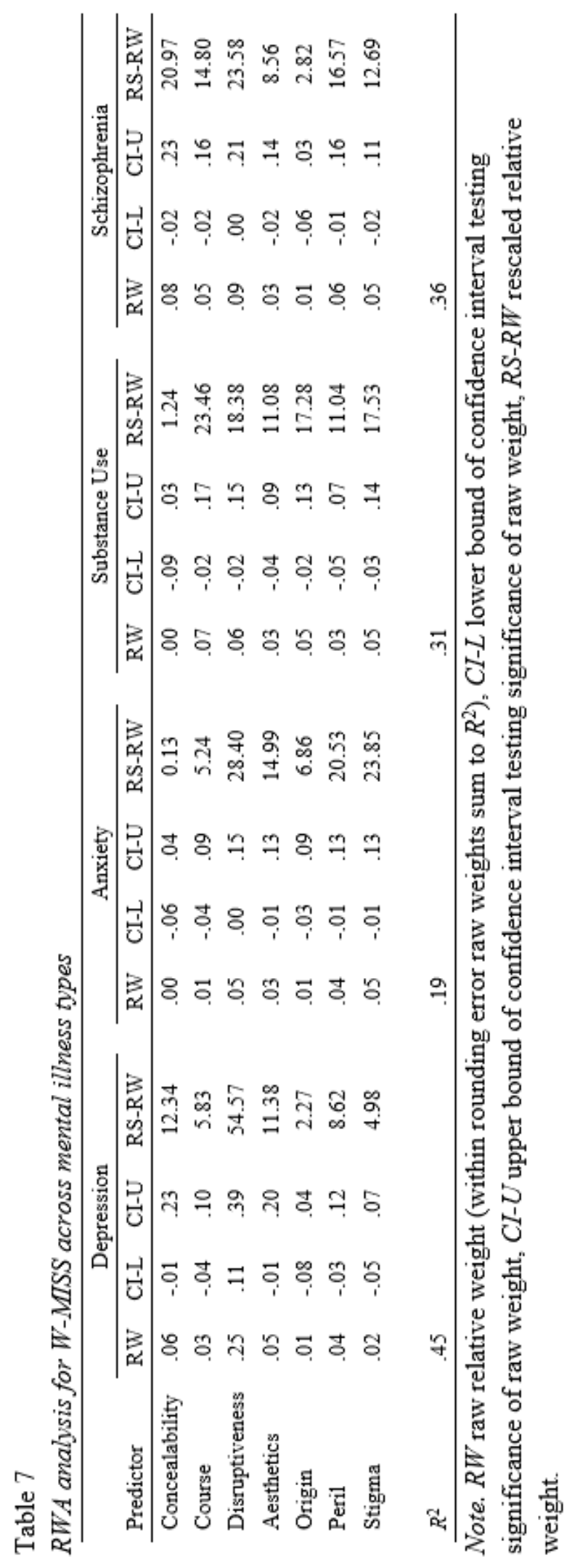




\section{Figures}




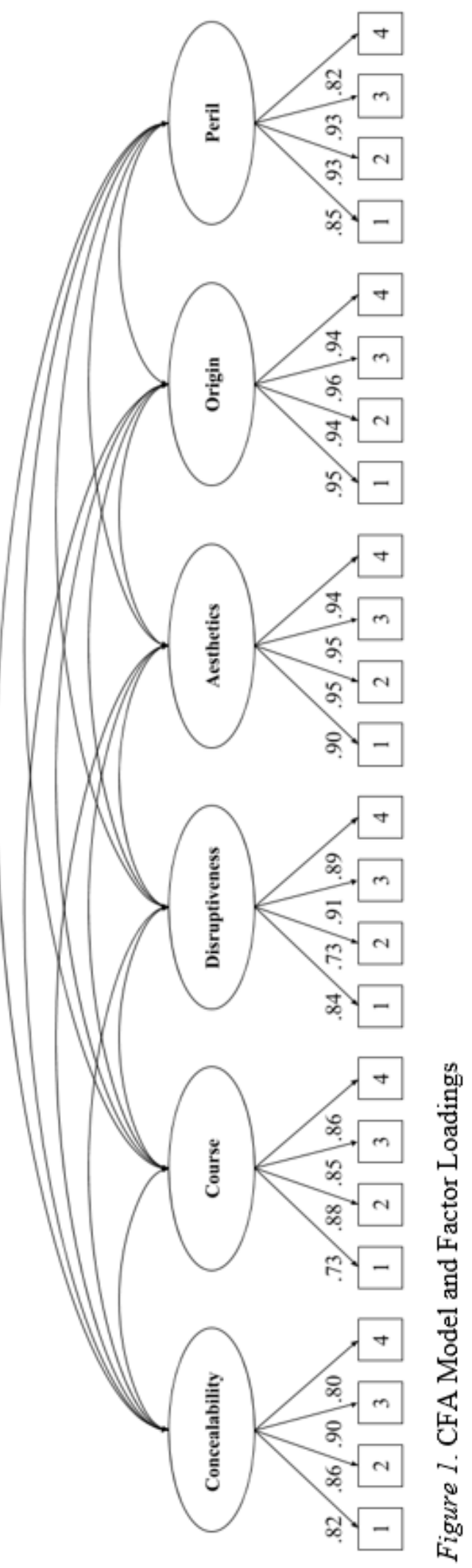




\section{References}

Aberson, C. L., Healy, M., \& Romero, V. (2000) Ingroup bias and self-esteem: A metaanalysis, Social Behavior and Personality, 27, 17-28. https://doi.org/10.1207/S15327957PSPR0402_04

Abrams, D., \& Hogg, M. A. (1988). Comments on the motivational status of self-esteem in social identity and intergroup discrimination. European Journal of Social Psychology, 18, 317-334. https://doi.org/10.1002/ejsp.242018040

Ajzen, I. (2012). Martin Fishbein's legacy: The reasoned action approach. The Annals of the American Academy of Political and Social Science, 640, 11-27. https://doi.org/10.1177/0002716211423363

Ajzen, I., \& Fishbein, M. (1977). Attitude-behavior relations: A theoretical analysis and review of empirical research. Psychological Bulletin, 84, 888-918. https://doi.org/10.1037/0033-2909.84.5.888

Altemeyer, B. (1981). Right-wing authoritarianism. University of Manitoba Press. American Psychiatric Association. (2013). Diagnostic and statistical manual of mental disorders, DSM-5 (5th ed.). Arlington, VA: American Psychiatric Association Publishing.

Anderson, J. C., \& Gerbing, D. W. (1991). Predicting the performance of measures in a confirmatory factor analysis with a pretest assessment of their substantive validities. Journal of Applied Psychology, 76, 732-740.

https://doi.org/10.1037/0021-9010.76.5.732 
Bartlett, M. S. (1950). Tests of significance in factor analysis. British Journal of Statistical Psychology, 3, 77-85. https://doi.org/10.1111/j.20448317.1950.tb00285.x

Briner, R. B., Amati, C., \& Lardner, R. (2003). Development of internal company standards of good management practice and a task-based risk assessment tool for offshore work-related stressors. Research Report RR107. HSE Books: Sudbury.

Brown, T. A., \& Moore, M. T. (2012). Confirmatory factor analysis. In R. H. Hoyle (Ed.), Handbook of structural equation modeling (pp. 361-379). New York, NY: Guilford Press.

Buhrmester, M. D., Kwang, T., \& Gosling, S. D. (2011). Amazon's Mechanical Turk: A new source of inexpensive, yet high-quality, data? Perspectives on Psychological Science: A Journal of the Association for Psychological Science, 6, 3-5. https://doi.org/10.1177/1745691610393980

Buhrmester, M. D., Talaifar, S., \& Gosling, S. D. (2018). An evaluation of Amazon's Mechanical Turk, its rapid rise, and its effective use. Perspectives on Psychological Science: A Journal of the Association for Psychological Science, 13, 149-154. https://doi.org/10.1177/1745691617706516

Campbell, D. T., \& Fiske, D. W. (1959). Convergent and discriminant validation by the multitrait-multimethod matrix. Psychological Bulletin, 56, 81-105. https://doi.org/10.1037/h0046016 
Center for Disease Control and Prevention. (2016). Mental illness. Retrieved from https://www.cdc.gov/mentalhealth/basics/mental-illness.htm. Accessed October 19, 2017.

Chin, M. G., Fisak, B., \& Sims, V. K. (2002). Development of the attitudes toward vegetarians scale. Anthrozoös, 15, 332-342. https://doi.org/10.2752/089279302786992441

Clair, J. A., Beatty, J. E., \& Maclean, T. L. (2005). Out of sight but not out of mind: Managing invisible social identities in the workplace. Academy of Management Review, 30, 78-95. https://doi.org/10.5465/amr.2005.15281431

Colella, A. (2001). Coworker distributive fairness judgments of the workplace accommodation of employees with disabilities. Academy of Management Review, 26, 100-116. https://doi.org/10.5465/amr.2001.4011984

Corrigan, P. W. (2005). On the stigma of mental illness: Practical strategies for research and social change. Washington, DC, US: American Psychological Association. Corrigan, P. W., Druss, B. G., \& Perlick, D. A. (2014). The impact of mental illness stigma on seeking and participating in mental health care. Psychological Science in the Public Interest, 15, 37-70. https://doi.org/10.1177/1529100614531398

Corrigan, P. W., River, L. P., Lundin, R. K., Penn, D. L., Uphoff-Wasowski, K., Campion, J., ... Kubiak, M. A. (2001). Three strategies for changing attributions about severe mental illness. Schizophrenia Bulletin, 27, 187-195. https://doi.org/10.1093/oxfordjournals.schbul.a006865 
Crandall, C. S., \& Reser, A. H. (2005). Attributions and anti-fat bias. In K. D. Brownell, R. M. Puhl, \& M. B. Schwartz (Eds.), Weight bias: Nature, consequences and remedies (pp. 83-96). New York, NY: Guilford.

Creed, W. E. D., \& Scully, M. A. (2000). Songs of ourselves: Employees' deployment of social identity in workplace encounters. Journal of Management Inquiry, 9, 391412. https://doi.org/10.1177/105649260000900410

Crom, D. B., Ness, K. K., Martinez, L. R., Hebl, M. R., Robison, L. L., Hudson, M. M., \& Brinkman, T. M. (2018). Workplace experiences and turnover intention among adult survivors of childhood cancer. Journal of Cancer Survivorship, 1-10. https://doi.org/10.1007/s11764-018-0686-8

Crowne, D. P., \& Marlowe, D. (1960). A new scale of social desirability independent of psychopathology. Journal of Consulting Psychology, 24, 349-354. https://doi.org/10.1037/h0047358

de Lange, A. H. D., Taris, T. W., Kompier, M. A. J., Houtman, I. L. D., \& Bongers, P. M. (2004). The relationships between work characteristics and mental health: Examining normal, reversed and reciprocal relationships in a 4-wave study. Work \& Stress, 18, 149-166. https://doi.org/10.1080/02678370412331270860

DeVellis, R. F. (2003). Scale development: Theory and applications (2nd ed.). Thousand Oaks, CA: Sage Publications, Inc.

Dimoff, J. K., \& Kelloway, E. K. (2019). With a little help from my boss: The impact of workplace mental health training on leader behaviors and employee resource 
utilization. Journal of Occupational Health Psychology, 24, 4-19.

https://doi.org/10.1037/ocp0000126

Dimoff, J. K., \& Kelloway, E. K. (2016). Resource utilization model: Organizational leaders as resource facilitators. In W. A. Gentry, C. Clerkin, P. L. Perrewé, J. R. B. Halbesleben, \& C. C. Rosen (Eds.), The Role of Leadership in Occupational Stress (Vol. 14, pp. 141-160). Bingley, UK: Emerald Group Publishing Limited.

Dimoff, J. K., Kelloway, E. K., \& Burnstein, M. D. (2016). Mental health awareness training (MHAT): The development and evaluation of an intervention for workplace leaders. International Journal of Stress Management, 23, 167-189. https://doi.org/10.1037/a0039479

DiStefano, C., \& Motl, R. W. (2006). Further investigating method effects associated with negatively worded items on self-report surveys. Structural Equation Modeling: A Multidisciplinary Journal, 13, 440-464. https://doi.org/10.1207/s15328007sem1303_6

Dovidio, J. F., \& Gaertner, S. L. (2010). Intergroup bias. In S. T. Fiske, D. T. Gilbert, \& G. Lindzey (Eds.), Handbook of social psychology (5th ed., Vol. 2, pp. 10841121). Hoboken, NJ: John Wiley \& Sons, Inc.

EEOC (2019). Charge statistics (Charges filed with EEOC) [Data table]. Retrieved from https://www.eeoc.gov/eeoc/statistics/enforcement/charges.cfm

Ellis, A. M., Casey, T. W., \& Krauss, A. D. (2017). Setting the foundation for well-being: Evaluation of a supervisor-focused mental health training. Occupational Health Science, 1, 67-88. https://doi.org/10.1007/s41542-017-0005-1 
Fabrigar, L. R., Wegener, D. T., MacCallum, R. C., \& Strahan, E. J. (1999). Evaluating the use of exploratory factor analysis in psychological research. Psychological Methods, 4, 272-299. https://doi.org/10.1037/1082-989X.4.3.272

Farina, A., Felner, R. D., \& Boudreau, L. A. (1973). Reactions of workers to male and female mental patient job applicants. Journal of Consulting and Clinical Psychology, 41, 363-372. https://doi.org/10.1037/h0035329

Farina, A., \& Hagelauer, H. D. (1975). Sex and mental illness: The generosity of females. Journal of Consulting and Clinical Psychology, 43, 122. https://doi.org/http://dx.doi.org.proxy.lib.pdx.edu/10.1037/h0076516

Farina, A., Murray, P. J., \& Groh, T. (1978). Sex and worker acceptance of a former mental patient. Journal of Consulting and Clinical Psychology, 46, 887-891. https://doi.org/10.1037/0022-006X.46.5.887

Feitosa, J., Joseph, D. L., \& Newman, D. A. (2015). Crowdsourcing and personality measurement equivalence: A warning about countries whose primary language is not English. Personality and Individual Differences, 75, 47-52. https://doi.org/10.1016/j.paid.2014.11.017

Feldman, D. B., \& Crandall, C. S. (2007). Dimensions of mental illness stigma: What about mental illness causes social rejection? Journal of Social and Clinical Psychology, 26, 137-154. https://doi.org/10.1521/jscp.2007.26.2.137

Fiske, S. T., \& Neuberg, S. L. (1990). A continuum of impression formation, from category-based to individuating processes: Influences of information and motivation on attention and interpretation. In M. Zanna (Ed.), Advances in 
experimental social psychology (Vol. 23, pp. 1-74). San Diego, CA: Academic Press.

Follmer, K. B., \& Jones, K. S. (2018). Mental illness in the workplace: An interdisciplinary review and organizational research agenda. Journal of Management, 44, 325-351. https://doi.org/10.1177/0149206317741194

Ford, J. K., MacCallum, R. C., \& Tait, M. (1986). The application of exploratory factor analysis in applied psychology: A critical review and analysis. Personnel Psychology, 39, 291-314. https://doi.org/10.1111/j.1744-6570.1986.tb00583.x

Gerbing, D. W., \& Anderson, J. C. (1988). An updated paradigm for scale development incorporating unidimensionality and its assessment. Journal of Marketing Research, 25, 186-192. https://doi.org/10.1177/002224378802500207

Goffman, E. (1963). Stigma: Notes on the management of spoiled identity. Englewood Cliffs, NJ: Prentice Hall.

Gouvier, W. D., Steiner, D. D., Jackson, W. T., Schlater, D., \& Rain, J. S. (1991). Employment discrimination against handicapped job candidates: An analog study of the effects of neurological causation, visibility of handicap, and public contact. Rehabilitation Psychology, 36, 121-129. https://doi.org/10.1037/h0079077

Griffiths, K. M., Christensen, H., Jorm, A. F., Evans, K., \& Groves, C. (2004). Effect of web-based depression literacy and cognitive-behavioural therapy interventions on stigmatising attitudes to depression: Randomised controlled trial. The British Journal of Psychiatry: The Journal of Mental Science, 185, 342-349.

https://doi.org/10.1192/bjp.185.4.342 
Guadagnoli, E., \& Velicer, W. (1988). Relation of Sample Size to the Stability of Component Patterns. Psychological Bulletin, 103, 265-275. https://doi.org/10.1037//0033-2909.103.2.265

Hair, J. F., Black, W. C., Babin, B. J., \& Anderson, R. E. (2009). Multivariate data analysis (7th ed.). Upper Saddle River, NJ: Pearson.

Harman, H. H. (1976). Modern factor analysis. University of Chicago Press.

Harmon-Jones, E., Simon, L., Greenberg, J., Pyszczynski, T., Solomon, S., \& McGregor, H. (1997). Terror management theory and self-esteem: Evidence that increased self-esteem reduces mortality salience effects. Journal of Personality and Social Psychology, 72, 24-36. https://doi.org/10.1037//0022-3514.72.1.24

Harrison, D. A., \& McLaughlin, M. E. (1993). Cognitive processes in self-report responses: Tests of item context effects in work attitude measures. Journal of Applied Psychology, 78, 129-140. https://doi.org/10.1037/0021-9010.78.1.129

Harvey, R. J., Billings, R. S., \& Nilan, K. J. (1985). Confirmatory factor analysis of the job diagnostic survey: Good news and bad news. Journal of Applied Psychology, 70, 461-468. https://doi.org/10.1037/0021-9010.70.3.461

Hayton, J. C., Allen, D. G., \& Scarpello, V. (2004). Factor retention decisions in exploratory factor analysis: A tutorial on parallel analysis. Organizational Research Methods, 7, 191-205. https://doi.org/10.1177/1094428104263675

Hebl, M. R., Foster, J. B., Mannix, L. M., \& Dovidio, J. F. (2002). Formal and interpersonal discrimination: A field study of bias toward homosexual applicants. 
Personality and Social Psychology Bulletin, 28, 815-825.

https://doi.org/10.1177/0146167202289010

Hebl, M. R., Ruggs, E. N., Martinez, L. R., Trump-Steele, R., \& Nittrouer, C. (2015). Understanding and reducing interpersonal discrimination in the workplace. In T. D. Nelson (Ed.), Handbook of Prejudice, Stereotyping, and Discrimination (2nd ed., pp. 387-407). New York, NY: Psychology Press.

Hebl, M. R., \& Skorinko, J. L. (2005). Acknowledging one's physical disability in the interview: Does "when” make a difference? Journal of Applied Social Psychology, 35, 2477-2492. https://doi.org/10.1111/j.1559-1816.2005.tb02111.x

Hendrickson, A. E., \& White, P. O. (1964). Promax: A quick method for rotation to oblique simple structure. British Journal of Statistical Psychology, 17, 65-70. https://doi.org/10.1111/j.2044-8317.1964.tb00244.x

Hill, D. B., \& Willoughby, B. L. B. (2005). The development and validation of the genderism and transphobia scale. Sex Roles, 53, 531-544. https://doi.org/10.1007/s11199-005-7140-x

Hinkin, T. R. (1998). A brief tutorial on the development of measures for use in survey questionnaires. Organizational Research Methods, 1, 104-121. https://doi.org/10.1177/109442819800100106

Hinshaw, S. P. (2006). Stigma and mental illness: Developmental issues and future prospects. In D. Cicchetti \& D. J. Cohen (Eds.), Developmental psychopathology: Risk, disorder, and adaptation (3rd ed., pp. 841-881). New York, NY: WileyBlackwell. 
Horn, J. L. (1965). A rationale and test for the number of factors in factor analysis. Psychometrika, 30, 179-185. https://doi.org/10.1007/BF02289447

Hu, L., \& Bentler, P. M. (1999). Cutoff criteria for fit indexes in covariance structure analysis: Conventional criteria versus new alternatives. Structural Equation Modeling: A Multidisciplinary Journal, 6, 1-55. https://doi.org/10.1080/10705519909540118

Insel, T. R. (2008). Assessing the economic costs of serious mental illness. American Journal of Psychiatry, 165, 663-665. https://doi.org/10.1176/appi.ajp.2008.08030366

Jones, A. M. (2011). Disclosure of mental illness in the workplace: A literature review. American Journal of Psychiatric Rehabilitation, 14, 212-229. https://doi.org/10.1080/15487768.2011.598101

Jones, E. E., Farina, A., Hastorf, A. H., Markus, H., Miller, D. T., \& Scott, R. A. (1984). Social stigma: The psychology of marked relationships. New York, NY: W. H. Freeman and Company.

Jones, K. P., \& King, E. B. (2014). Managing concealable stigmas at work: A review and multilevel model. Journal of Management, 40, 1466-1494. https://doi.org/10.1177/0149206313515518

Jöreskog, K. G., \& Sörbom, D. (1989). LISREL 7: A guide to the program and applications. Chicago, IL: SPSS.

Kessler, R. C., Berglund, P., Demler, O., Jin, R., Merikangas, K. R., \& Walters, E. E. (2005). Lifetime prevalence and age-of-onset distributions of DSM-IV disorders 
in the national comorbidity survey replication. Archives of General Psychiatry, 62, 593-602. https://doi.org/10.1001/archpsyc.62.6.593

Kim, J.-O., \& Mueller, C. W. (1978). Factor analysis: Statistical methods and practical issues. SAGE.

King, E. B., Shapiro, J. R., Hebl, M. R., Singletary, S. L., \& Turner, S. (2006). The stigma of obesity in customer service: A mechanism for remediation and bottomline consequences of interpersonal discrimination. Journal of Applied Psychology, 91, 579-593. https://doi.org/10.1037/0021-9010.91.3.579

Kitchener, B. A., \& Jorm, A. F. (2004). Mental health first aid training in a workplace setting: A randomized controlled trial. BMC Psychiatry, 4, 23. https://doi.org/10.1186/1471-244X-4-23

Kleck, R. (1968). Physical stigma and nonverbal cues emitted in face-to-face interaction. Human Relations, 21, 19-28. https://doi.org/10.1177/001872676802100102

Kline, R. B. (2010). Principles and practice of structural equation modeling (3rd ed.). New York, NY: The Guilford Press.

Kossek, E. E., \& Zonia, S. C. (1993). Assessing diversity climate: A field study of reactions to employer efforts to promote diversity. Journal of Organizational Behavior, 14, 61-81. https://doi.org/10.1002/job.4030140107

Krupa, T., Kirsh, B., Cockburn, L., \& Gewurtz, R. (2009). Understanding the stigma of mental illness in employment. Work, 33, 413-425. https://doi.org/10.3233/WOR2009-0890 
Lin, N. (1986). Conceptualizing social support. In N. Lin, A. Dean, \& W. M. Ensel (Eds.), Social support, life events, and depression (pp. 17-31). New York, NY: Academic Press, Inc.

Linnan, L., Bowling, M., Childress, J., Lindsay, G., Blakey, C., Pronk, S., ... Royall, P. (2008). Results of the 2004 national worksite health promotion survey. American Journal of Public Health, 98, 1503-1509. https://doi.org/10.2105/AJPH.2006.100313

Luoma, J. B., O’Hair, A. K., Kohlenberg, B. S., Hayes, S. C., \& Fletcher, L. (2010). The development and psychometric properties of a new measure of perceived stigma toward substance users. Substance Use \& Misuse, 45, 47-57. https://doi.org/10.3109/10826080902864712

Lyons, B. J., Martinez, L. R., Ruggs, E. N., Hebl, M. R., Ryan, A. M., O’Brien, K. R., \& Roebuck, A. (2018). To say or not to say: Different strategies of acknowledging a visible disability. Journal of Management, 44, 1980-2007. https://doi.org/10.1177/0149206316638160

Major, B., \& O’Brien, L. T. (2005). The Social psychology of stigma. Annual Review of Psychology, 56, 393-421. https://doi.org/10.1146/annurev.psych.56.091103.070137

Martinez, L. R., \& Hebl, M. R. (2016). Adult survivors of childhood cancers' identity disclosures in the workplace. Journal of Cancer Survivorship, 10, 416-424. https://doi.org/10.1007/s11764-015-0487-2 
Martinez, L. R., White, C. D., Shapiro, J. R., \& Hebl, M. R. (2016). Selection BIAS: Stereotypes and discrimination related to having a history of cancer. Journal of Applied Psychology, 101, 122-128. https://doi.org/10.1037/ap10000036

McKiernan, F., Spreadbury, J., Carr, T., \& Waller, G. (2013). Psychological aspects of bereavement in adults: Preliminary development of the bereavement experiences index. Journal of Social Work in End-of-Life \& Palliative Care, 9, 7-26. https://doi.org/10.1080/15524256.2012.758603

Meade, A. W., \& Craig, S. B. (2012). Identifying careless responses in survey data. Psychological Methods, 17, 437-455. https://doi.org/10.1037/a0028085

Mental Health Commission of Canada. (2011). Improving psychological health and safety in the workplace: Cricial analysis and pragmatic options. Retrieved from http://www.mentalhealthcommission.ca/sites/default/files/Workforce_Integrated_ Approach_Framework\%252520_ENG_0.pdf.

Morrison, T. G., \& O'connor, W. E. (1999). Psychometric properties of a scale measuring negative attitudes toward overweight individuals. The Journal of Social Psychology, 139, 436-445. https://doi.org/10.1080/00224549909598403

National Institute of Mental Health. (n.d.). Any mental illness (AMI) among adults. Retrieved October 23, 2015.

Nieuwenhuijsen, K., Verbeek, J. H. a. M., de Boer, A. G. E. M., Blonk, R. W. B., \& van Dijk, F. J. H. (2004). Supervisory behaviour as a predictor of return to work in employees absent from work due to mental health problems. Occupational and Environmental Medicine, 61, 817-823. https://doi.org/10.1136/oem.2003.009688 
Nittrouer, C. L., Trump, R. C. E., O’Brien, K. R., \& Hebl, M. (2014). Stand up and be counted: In the long run, disclosing helps all. Industrial and Organizational Psychology: Perspectives on Science and Practice, 7, 235-241. https://doi.org/10.1111/iops.12139

Nunally, J. C. (1978). Psychometric theory. New York, NY: McGraw-Hill.

Oakie, T., Smith, N. A., Dimoff, J. K., \& Kelloway, E. K. (2018). Helping oneself and helping others: Evaluating the impact of the Coworker Health Awareness Training (CHAT) program. Manuscript submitted for publication.

Onken, S. J., \& Slaten, E. (2000). Disability identity formation and affirmation: The experiences of persons with severe mental illness. Sociological Practice, 2, 99111. https://doi.org/10.1023/A:1010136801075

Perry, E. L., \& Finkelstein, L. M. (1999). Toward a broader view of age discrimination in employment-related decisions: A joint consideration of organizational factors and cognitive processes. Human Resource Management Review, 9, 21-49. https://doi.org/10.1016/S1053-4822(99)00010-8

Podsakoff, P. M., MacKenzie, S. B., Lee, J.-Y., \& Podsakoff, N. P. (2003). Common method biases in behavioral research: A critical review of the literature and recommended remedies. Journal of Applied Psychology, 88, 879-903. https://doi.org/10.1037/0021-9010.88.5.879

Pratto, F., Sidanius, J., Stallworth, L. M., \& Malle, B. F. (1994). Social dominance orientation: A personality variable predicting social and political attitudes. 
Journal of Personality and Social Psychology, 67, 741-763.

https://doi.org/10.1037/0022-3514.67.4.741

Price, J. L., \& Mueller, C. W. (1986). Handbook of organizational measurement. Marshfield, MA: Pitman Publishing.

Ragins, B. R. (2008). Disclosure disconnects: Antecedents and consequences of disclosing invisible stigmas across life domains. Academy of Management Review, 33, 194-215. https://doi.org/10.5465/amr.2008.27752724

Reynolds, W. M. (1982). Development of reliable and valid short forms of the MarloweCrowne Social Desirability Scale. Journal of Clinical Psychology, 38, 119-125. https://doi.org/10.1002/1097-4679(198201)38:1<119::AIDJCLP2270380118>3.0.CO;2-I

Richman, W. L., Kiesler, S., Weisband, S., \& Drasgow, F. (1999). A meta-analytic study of social desirability distortion in computer-administered questionnaires, traditional questionnaires, and interviews. Journal of Applied Psychology, 84, 754-775. https://doi.org/10.1037/0021-9010.84.5.754

Robinson, L., Kocum, L., Loughlin, C., Bryson, L., \& Dimoff, J. K. (2015). I wanted you to know: Breast cancer survivors' control of workplace communication about cancer. Journal of Occupational Health Psychology, 20, 446-456.

https://doi.org/10.1037/a0039142

Roosevelt, M. (2019, April 16). In the age of legal marijuana, many employers drop 'zero tolerance' drug tests. The Sacramento Bee. Retrieved from https://www.sacbee.com 
Rosenberg, M. (1979). Conceiving the self. New York, NY: Basic Books.

Rubin, M., \& Hewstone, M. (1998). Social identity theory's self-esteem hypothesis: A review and some suggestions for clarification. Personality and Social Psychology Review, 2,40-62. https://doi.org/10.1207/s15327957pspr0201_3

Rummel, R. J. (1970). Applied factor analysis. Evanston, IL: Northwestern University Press.

Substance Abuse and Mental Health Services Administration. (2018). Key substance use and mental health indicators in the United States: Results from the 2017 National Survey on Drug Use and Health (HHS Publication No. SMA 18-5068, NSDUH Series H-53). Retrieved from https://www.samhsa.gov/data/

Schmitt, D., \& Allik, J. (2005). Simultaneous administration of the rosenberg self-esteem scale in 53 nations: Exploring the universal and culture-specific features of global self-esteem. Journal of Personality and Social Psychology, 89, 623-642. https://doi.org/10.1037/0022-3514.89.4.623

Schmitt, N., \& Stults, D. M. (1986). Methodology review: Analysis of multitraitmultimethod matrices. Applied Psychological Measurement, 10, 1-22. https://doi.org/10.1177/014662168601000101

Schneider, D. J. (2004). The psychology of stereotyping. New York, NY: The Guilford Press.

Schomerus, G., Evans-Lacko, S., Rüsch, N., Mojtabai, R., Angermeyer, M. C., \& Thornicroft, G. (2015). Collective levels of stigma and national suicide rates in 25 
European countries. Epidemiology and Psychiatric Sciences, 24, 166-171. https://doi.org/10.1017/S2045796014000109

Schomerus, G., Schwahn, C., Holzinger, A., Corrigan, P. W., Grabe, H. J., Carta, M. G., \& Angermeyer, M. C. (2012). Evolution of public attitudes about mental illness: a systematic review and meta-analysis. Acta Psychiatrica Scandinavica, 125, 440452. https://doi.org/10.1111/j.1600-0447.2012.01826.x

Schriesheim, C. A., Powers, K. J., Scandura, T. A., Gardiner, C. C., \& Lankau, M. J. (1993). Improving construct measurement in management research: Comments and a quantitative approach for assessing the theoretical content adequacy of paper-and-pencil survey-type instruments. Journal of Management, 19, 385-417. https://doi.org/10.1016/0149-2063(93)90058-U

Schumacher, M., Corrigan, P. W., \& Dejong, T. (2003). Examining cues that signal mental illness stigma. Journal of Social and Clinical Psychology, 22, 467-476. https://doi.org/10.1521/jscp.22.5.467.22926

Schwab, D. P. (1980). Construct validity in organization behavior. In B. M. Staw \& L. L. Cummings (Eds.), Research in organizational behavior (Vol. 2, pp. 3-43). Greenwich, CT: JAI.

Shaffer, J. A., \& Postlethwaite, B. E. (2012). A Matter of context: A meta-analytic investigation of the relative validity of contextualized and noncontextualized personality measures. Personnel Psychology, 65, 445-494. https://doi.org/10.1111/j.1744-6570.2012.01250.x 
Shore, L. M., Randel, A. E., Chung, B. G., Dean, M. A., Holcombe Ehrhart, K., \& Singh, G. (2011). Inclusion and diversity in work groups: A review and model for future research. Journal of Management, 37, 1262-1289. https://doi.org/10.1177/0149206310385943

Sieff, E. (2003). Media frames of mental illnesses: The potential impact of negative frames. Journal of Mental Health, 12, 259. https://doi.org/10.1080/0963823031000118249

Singletary, S. L., \& Hebl, M. R. (2009). Compensatory strategies for reducing interpersonal discrimination: The effects of acknowledgments, increased positivity, and individuating information. Journal of Applied Psychology, 94, 797-805. https://doi.org/10.1037/a0014185

Smith, N. A., Sabat, I. E., Martinez, L. R., Weaver, K., \& Xu, S. (2015). A convenient solution: Using MTurk to sample from hard-to-reach populations. Industrial and Organizational Psychology: Perspectives on Science and Practice, 8, 220-228. https://doi.org/10.1017/iop.2015.29

Sobel, D. (1981, August 4). Thousands with mental health insurance choose to pay own bill. The New York Times.

Soper, D. S. (2018). A-prior Sample Size Calculator for Structural Equation Models [Software]. Available from http://www.danielsport.com/statcalc.

Spector, P. E. (1992). Summated rating scale construction: An introduction. SAGE. 
Starbucks. (2018). Starbucks to close all stores nationwide for racial-bias education on May 29 (Press release). Retrieved from https://news.starbucks.com/pressreleases/starbucks-to-close-stores-nationwide-for-racial-bias-education-may-29

Stone, D. L., \& Colella, A. (1996). A model of factors affecting the treatment of disabled individuals in organizations. Academy of Management Review, 21, 352-401. https://doi.org/10.5465/amr.1996.9605060216

Tabachnick, B. G., \& Fidell, L. S. (2012). Using multivariate statistics (6th ed.). Boston: Pearson.

Tajfel, H., \& Turner, J. C. (1986). The social identity theory of intergroup behavior. In S. Worchel \& W. G. Austin (Eds.), Psychology of intergroup relations (2nd ed.). Chicago, IL: Nelson-Hall Publishers.

Teeraananchai, S., Kerr, S. J., Amin, J., Ruxrungtham, K., \& Law, M. G. (2016). Life expectancy of HIV-positive people after starting combination antiretroviral therapy: A meta-analysis. HIV Medicine, 18, 256-266. https://doi.org/10.1111/hiv.12421

Tonidandel, S., \& LeBreton, J. M. (2011). Relative importance analysis: A useful supplement to regression analysis. Journal of Business and Psychology, 26, 1-9. https://doi.org/10.1007/s10869-010-9204-3

Tonidandel, S., \& LeBreton, J. M. (2015). RWA web: A free, comprehensive, web-based, and user friendly tool for relative weight analyses. Journal of Business and Psychology, 30, 207-216. https://doi.org/10.1007/s10869-014-9351-z 
Tonidandel, S., LeBreton, J. M., \& Johnson, J. W. (2009). Determining the statistical significance of relative weights. Psychological Methods, 14, 387-399. https://doi.org/10.1037/a0017735

Walch, S. E., Ngamake, S. T., Francisco, J., Stitt, R. L., \& Shingler, K. A. (2012). The attitudes toward transgendered individuals scale: Psychometric properties. Archives of Sexual Behavior, 41, 1283-1291. https://doi.org/10.1007/s10508-0129995-6

Walker, E. R., McGee, R. E., \& Druss, B. G. (2015). Mortality in mental disorders and global disease burden implications: A systematic review and meta-analysis. JAMA Psychiatry, 72, 334-341. https://doi.org/10.1001/jamapsychiatry.2014.2502

Walter, S. L., Seibert, S. E., Goering, D., \& O’Boyle, E. H. (2018). A tale of two sample sources: Do results from online panel data and conventional data converge? Journal of Business and Psychology. Advanced online publication. https://doi.org/10.1007/s10869-018-9552-y

Whitley, B. E. (1999). Right-wing authoritarianism, social dominance orientation, and prejudice. Journal of Personality and Social Psychology, 77, 126-134. https://doi.org/10.1037/0022-3514.77.1.126

Worthington, R. L., \& Whittaker, T. A. (2006). Scale development research: A content analysis and recommendations for best practices. The Counseling Psychologist, 34, 806-838. https://doi.org/10.1177/0011000006288127 
Zakrisson, I. (2005). Construction of a short version of the right-wing authoritarianism (RWA) scale. Personality and Individual Differences, 39, 863-872. https://doi.org/10.1016/j.paid.2005.02.026

Zimet, G. D., Dahlem, N. W., Zimet, S. G., \& Farley, G. K. (1988). The multidimensional scale of perceived social support. Journal of Personality Assessment, 52, 30-41. https://doi.org/10.1207/s15327752jpa5201_2 
Appendix A: SME Instruction Sheet 


\section{INSTRUCTIONS}

Please use the following Google sheet when writing potential items. As I have 10 SMEs generating items in total, feel free to write between 1 and 5 items for each dimension.

The purpose of this scale is to be used as a measure of workplace stigma regarding mental illness. However, I also envision this scale as appropriate for other stigmatized identities. As such, please think about developing items that would be appropriate for any number of stigmatized identities.

Also, please keep in mind the following guidelines when developing items:

1) Items should utilize clear and concise statements.

2) Items should be written with language that would be considered familiar - that is, please avoid jargon, expressions, and colloquial language.

3) Items should be written at a high school reading level or below.

4) Please write items that reflect stereotypic cognitions (i.e., beliefs; not emotions or behaviors) with regard to each of the dimensions.

5) Each single item should address a single stereotypic cognition or belief; double-barreled items should be avoided.

6) Item may be redundant with one another in terms of general content, but should differ in sentence structure and with regard to the particular terminology used

7) Avoid leading items. Although the items are addressing stereotypic cognitions, they should be written in such a way that they are assessed as generally "neutral" so that participants may more freely choose to endorse (or not endorse) specific items.

8) Avoid providing negatively-worded ("not") items.

Finally, the definitions of each dimension are listed below (and in the google sheet provided).

Concealability: The extent to which the stigma is hidden or obvious and the extent to which one can control how visible the stigma is.

Course: The extent to which the stigma may or may not change over time and the perceived ultimate outcome of the stigma.

Disruptiveness: The extent to which the stigma blocks or hampers interactions and communications with others.

Aesthetics: The extent to which the stigma is perceived as repellent, ugly, or upsetting in terms of its aesthetic qualities.

Origin: The perceived origin of the stigma. That is, the extent to which the individual with the stigma is perceived as responsible for having the stigma (often thought of as the perceived controllability of the stigma).

Peril: The perceived danger posed by the stigma either to oneself or to others, including the extent to which the danger is perceived as imminent and serious. 
Appendix B: Scale Items 


\section{W-MISS}

Instructions: Please rate the extent to which you agree with the following items on a 7point scale ( 1 = "Agree not at all," 7 = "Agree very much").

\section{Concealability}

1. At work, it tends to be difficult to tell when someone has a mental illness.

2. Employees with mental illnesses can hide their symptoms from others in the workplace.

3. Unless an employee discloses that they have a mental illness, it is unlikely other people at work would know.

4. Symptoms of mental illnesses tend to be concealable in the workplace.

\section{Course}

1. Employees with mental illnesses usually have these problems for life.

2. Employees with mental illnesses rarely recover.

3. Employees with mental illnesses are unlikely to be cured.

4. Employees with mental illnesses tend to have a chronic condition that cannot be helped.

\section{Disruptiveness}

1. Employees with mental illnesses tend to have difficulty communicating well with others at work.

2. Employees with mental illnesses can have a difficult time interacting with others at work. 
3. Employees with mental illnesses tend to have a difficult time being good team players.

4. Employees with mental illnesses tend to be exhausting to interact with at work.

\section{Aesthetics}

1. Employees with mental illnesses tend to have poor hygiene at work.

2. Employees with mental illnesses tend to smell bad.

3. Employees with mental illnesses tend to look disheveled.

4. Employees with mental illnesses tend to look unkempt.

\section{Origin}

1. Employees with mental illnesses tend to be responsible for their condition.

2. Employees with mental illnesses often only have themselves to blame for their condition.

3. Employees who have mental illnesses likely could have prevented them.

4. Mental illnesses tend to only affect employees who are weak.

\section{Peril}

1. Employees with mental illnesses can be violent at work.

2. Employees with mental illnesses are likely to hurt someone else at work.

3. Employees with mental illnesses are likely to pose a threat to public safety.

4. Employees with a mental illness are likely a danger to themselves. 


\section{General Stigma Toward Mental Illness}

Instructions: Please respond with the extent to which you agree with the following items on a 7-point scale ( 1 = "Strongly Disagree," 7 = "Strongly Agree").

1. People with mental health problems could snap out of it if they wanted.

2. Mental health problems are a sign of personal weakness.

3. Mental health problems are not a real medical illness. (R)

4. People with mental health problems are dangerous.

5. It is best to avoid people with mental health problems so you don't develop the problem.

6. People with mental health problems are unpredictable.

7. If I had a mental health problem I would not tell anyone.

8. I would not employ someone if I knew they had a mental health problem.

9. I would not vote for a politician if I knew they had a mental health problem. 


\section{Right-Wing Authoritarianism}

Instructions: Please respond with the extent to which you agree with the following items on a 7-point scale (1 = "Strongly Disagree," 7 = "Strongly Agree").

1. Our country needs a powerful leader, in order to destroy the radical and immoral currents prevailing in society today.

2. Our country needs free thinkers, who will have the courage to stand up against traditional ways, even if this upsets many people.

3. The "old-fashioned ways" and "old-fashioned values" still show the best way to live.

4. Our society would be better off if we showed tolerance and understanding for untraditional values and opinions. (R)

5. God's laws about abortion, pornography and marriage must be strictly followed before it is too late, violations must be punished.

6. The society needs to show openness towards people thinking differently, rather than a strong leader, the world is not particularly evil or dangerous. (R)

7. It would be best if newspapers were censored so that people would not be able to get hold of destructive and disgusting material.

8. Many good people challenge the state, criticize the church and ignore "the normal way of living." (R)

9. Our forefathers ought to be honored more for the way they have built our society, at the same time we ought to put an end to those forces destroying it. 
10. People ought to put less attention to the Bible and religion, instead they ought to develop their own moral standards. (R)

11. There are many radical, immoral people trying to ruin things; the society ought to stop them.

12. It is better to accept bad literature than to censor it. (R)

13. Facts show that we have to be harder against crime and sexual immorality, in order to uphold law and order.

14. The situation in the society of today would be improved if troublemakers were treated with reason and humanity. (R)

15. If the society so wants, it is the duty of every true citizen to help eliminate the evil that poisons our country from within. 


\section{Social Dominance Orientation}

Instructions: Which of the following objects or statements do you have a positive or negative feeling towards? Beside each object or statement, select the number from ' 1 ' (Extremely Negative) to '7' (Extremely Positive) which represents the degree of your positive or negative feeling.

1. We should strive to make incomes as equal as possible. (R)

2. Group equality should be our ideal. (R)

3. It's OK if some groups have more of a chance in life than others.

4. To get ahead in life, it is sometimes necessary to step on other groups.

5. We should do what we can to equalize conditions for different groups. (R)

6. It's probably a good thing that certain groups are at the top and others are at the bottom.

7. Inferior groups should stay in their place.

8. We would have fewer problems if groups were treated more equally. (R)

9. It would be good if groups could be equal. (R)

10. In getting what you want, it is sometimes necessary to use force against other groups.

11. All groups should be given an equal chance in life. (R)

12. If certain groups stayed in their place, we would have fewer problems.

13. We should strive for increased social equality. (R)

14. Sometimes other groups must be kept in their place.

15. Some groups of people are simply inferior to other groups. 
16. No one group should dominate in society. $(\mathrm{R})$

\section{Self-Esteem}

Instructions: Below is a list of statements dealing with your general feelings about yourself. Please indicate how strongly you agree or disagree with each statement." You will be asked to respond on a 7-point scale $(1=$ "Strongly Disagree," to $7=$ "Strongly Agree").

1. On the whole, I am satisfied with myself.

2. At times I think I am no good at all. (R)

3. I feel that I have a number of good qualities.

4. I am able to do things as well as most other people.

5. I feel I do not have much to be proud of. (R)

6. I certainly feel useless at times. (R)

7. I feel that I'm a person of worth, at least on an equal plane with others.

8. I wish I could have more respect for myself. (R)

9. All in all, I am inclined to feel that I am a failure. (R)

10. I take a positive attitude toward myself. 


\section{Social Desirability}

Instructions: Please indicate how strongly you agree or disagree with the following items on a 7-point scale ( 1 = "Strongly Disagree," 7 = "Strongly Agree").

1. It is sometimes hard for me to go on with my work if I am not encouraged. (R)

2. I sometimes feel resentful when I don't get my way. (R)

3. On a few occasions, I have given up doing something because I thought too little of my ability. (R)

4. There have been times when I felt like rebelling against people in authority even though I knew they were right. (R)

5. No matter who I'm talking to, I'm always a good listener.

6. There have been occasions when I took advantage of someone. (R)

7. I'm always willing to admit it when I make a mistake.

8. I sometimes try to get even rather than forgive and forget. (R)

9. I am always courteous, even to people who are disagreeable.

10. I have never been irked when people expressed ideas very different from my own.

11. There have been times when I was quite jealous of the good fortune of others. (R)

12. I am sometimes irritated by people who ask favors of me. (R)

13. I have never deliberately said something that hurt someone's feelings. 


\section{Social Support}

Instructions: Please indicate the extent you agree or disagree with the following items on

a 7-point scale (1 = "Strongly Disagree," 7 = "Strongly Agree").

1. There is a special person who is around when I am in need.

2. There is a special person with whom I can share my joys and sorrows.

3. My family really tries to help me.

4. I get the emotional help and support I need from my family.

5. I have a special person who is a real source of comfort to me.

6. My friends really try to help me.

7. I can count on my friend when things go wrong.

8. I can talk about my problems with my family.

9. I have friends with whom I can share my joys and sorrow.

10. There is a special person in my life who cares about my feelings.

11. My family is willing to help me make decisions.

12. I can talk about my problems with my friends. 


\section{Hireability}

Instructions: Please consider the job candidate when responding to the following, and rate the extent to which you agree with each item on a 7-point scale ( 1 = "Strongly Disagree," $7=$ "Strongly Agree").

1. I would recommend hiring the applicant.

2. I viewed the applicant as a quality candidate.

3. I liked the applicant as a potential employee.

4. I liked the applicant personally.

5. I felt the applicant would do well in a workplace scenario.

6. I anticipated the applicant would have on-the-job problems. (R)

7. I thought hiring the job applicant would be too risky. (R)

8. I thought the applicant would be a competent worker.

9. I felt there were too many red flags with the applicant. (R) 
Appendix C: Resume Stimuli 


\section{Mental Illness Stimulus}

\section{Taylor Johnson}

5423 Ashley Way Ct Sugar Land, TX 77479

Cell: 713-516-2281

Please note: There is a gap in my resume because I was diagnosed with a mental illness and could not work due to medical treatment.

PROFESSIONAL EXPERIENCE:

Jack's Carpet Sugar Land, TX

March 2015 - April 2017

Sales Consultant

- Responsibilities included selling flooring and customer relations, ordering product, scheduling installation jobs and coordinating work crews, product research, and distributor interaction

American Direct Inc Austin, TX

January 2014 - October 2014

Sales/Warehouse Manager

- Responsibilities included pitching sales presentations, closing deals, store opening and closing duties, payroll, supervising a 20 person phone room, customer relations, employee scheduling, organizing sales representative rotation, gross profit reports, reporting to upper management, among others.

- Promoted from sales associate in April 2007

Old San Francisco Steakhouse Houston, TX

March 2008 - May 2011

Floor Manager

- Responsibilities included customer relations, daily operations, daily set up and break down of the restaurant, serving tables and bartending when needed, supervision and support of the wait staff, taking in money and reports from wait staff at the end of shifts, among others.

Denny's Restaurant Missouri City, TX

June 2003 - July 2007

Shift Manager, Server

- Responsibilities included shift scheduling, inventory, serving tables, working the cash register, among others.

- I was promoted from server and given a raise during my employment here

EDUCATION:

University of Houston Houston, TX

May 2017

Bachelor of Science in Psychology, Business Administration minor

Clements High School Sugar Land, TX

HONORS:

- I am a member of Phi Theta Kappa (national honors society).

- University of Houston Dean's List (Spring 2016, Fall 2016, Spring 2017)

\section{REFERENCES:}

- Robin Smith, Supervisor, (646) 504-1651

- Additional references available upon request 


\section{Anxiety Disorder Stimulus}

\section{Taylor Johnson}

5423 Ashley Way Ct Sugar Land, TX 77479

Cell: 713-516-2281

Please note: There is a gap in my resume because I was diagnosed with an anxiety disorder and could not work due to medical treatment.

PROFESSIONAL EXPERIENCE:

Jack's Carpet Sugar Land, TX

March 2015 - April 2017

Sales Consultant

- Responsibilities included selling flooring and customer relations, ordering product, scheduling installation jobs and coordinating work crews, product research, and distributor interaction

American Direct Inc Austin, TX

January 2014 - October 2014

Sales/Warehouse Manager

- Responsibilities included pitching sales presentations, closing deals, store opening and closing duties, payroll, supervising a 20 person phone room, customer relations, employee scheduling, organizing sales representative rotation, gross profit reports, reporting to upper management, among others.

- Promoted from sales associate in April 2007

Old San Francisco Steakhouse Houston, TX

March 2008 - May 2011

Floor Manager

- Responsibilities included customer relations, daily operations, daily set up and break down of the restaurant, serving tables and bartending when needed, supervision and support of the wait staff, taking in money and reports from wait staff at the end of shifts, among others.

Denny's Restaurant Missouri City, TX

June 2003 - July 2007

Shift Manager, Server

- Responsibilities included shift scheduling, inventory, serving tables, working the cash register, among others.

- I was promoted from server and given a raise during my employment here

EDUCATION:

University of Houston Houston, TX

Bachelor of Science in Psychology, Business Administration minor

Clements High School Sugar Land, TX

HONORS:

- I am a member of Phi Theta Kappa (national honors society).

- University of Houston Dean's List (Spring 2016, Fall 2016, Spring 2017)

\section{REFERENCES:}

- Robin Smith, Supervisor, (646) 504-1651

- Additional references available upon request 


\section{Depression Stimulus}

\section{Taylor Johnson}

5423 Ashley Way Ct Sugar Land, TX 77479

Cell: 713-516-2281

Please note: There is a gap in my resume because I was diagnosed with depression and could not work due to medical treatment.

\section{PROFESSIONAL EXPERIENCE}

Jack's Carpet Sugar Land, TX

March 2015 - April 2017

Sales Consultant

- Responsibilities included selling flooring and customer relations, ordering product, scheduling installation jobs and coordinating work crews, product research, and distributor interaction

American Direct Inc Austin, TX

January 2014 - October 2014

Sales/Warehouse Manager

- Responsibilities included pitching sales presentations, closing deals, store opening and closing duties, payroll, supervising a 20 person phone room, customer relations, employee scheduling, organizing sales representative rotation, gross profit reports, reporting to upper management, among others.

- Promoted from sales associate in April 2007

Old San Francisco Steakhouse Houston, TX

Floor Manager

- Responsibilities included customer relations, daily operations, daily set up and break down of the restaurant, serving tables and bartending when needed, supervision and support of the wait staff, taking in money and reports from wait staff at the end of shifts, among others.

Denny's Restaurant Missouri City, TX

June 2003 - July 2007

Shift Manager, Server

- Responsibilities included shift scheduling, inventory, serving tables, working the cash register, among others.

- I was promoted from server and given a raise during my employment here

\section{EDUCATION:}

University of Houston Houston, TX

Bachelor of Science in Psychology, Business Administration minor

Clements High School Sugar Land, TX

HONORS:

- I am a member of Phi Theta Kappa (national honors society).

- University of Houston Dean's List (Spring 2016, Fall 2016, Spring 2017)

\section{REFERENCES:}

- Robin Smith, Supervisor, (646) 504-1651

- Additional references available upon request 


\title{
Substance Use Disorder Stimulus
}

\section{Taylor Johnson}

\author{
5423 Ashley Way Ct Sugar Land, TX 77479
}

Cell: 713-516-2281

Please note: There is a gap in my resume because I was diagnosed with substance use disorder and could not work due to medical treatment.

PROFESSIONAL EXPERIENCE:

Jack's Carpet Sugar Land, TX

March 2015 - April 2017

Sales Consultant

- Responsibilities included selling flooring and customer relations, ordering product, scheduling installation jobs and coordinating work crews, product research, and distributor interaction

American Direct Inc Austin, TX

January 2014 - October 2014

Sales/Warehouse Manager

- Responsibilities included pitching sales presentations, closing deals, store opening and closing duties, payroll, supervising a 20 person phone room, customer relations, employee scheduling, organizing sales representative rotation, gross profit reports, reporting to upper management, among others.

- $\quad$ Promoted from sales associate in April 2007

Old San Francisco Steakhouse Houston, TX

March 2008 - May 2011

Floor Manager

- Responsibilities included customer relations, daily operations, daily set up and break down of the restaurant, serving tables and bartending when needed, supervision and support of the wait staff, taking in money and reports from wait staff at the end of shifts, among others.

Denny's Restaurant Missouri City, TX

June 2003 - July 2007

Shift Manager, Server

- Responsibilities included shift scheduling, inventory, serving tables, working the cash register, among others.

- I was promoted from server and given a raise during my employment here

EDUCATION:

University of Houston Houston, TX

Bachelor of Science in Psychology, Business Administration minor

Clements High School Sugar Land, TX

HONORS:

- I am a member of Phi Theta Kappa (national honors society).

- University of Houston Dean's List (Spring 2016, Fall 2016, Spring 2017)

\section{REFERENCES:}

- Robin Smith, Supervisor, (646) 504-1651

- Additional references available upon request 


\section{Schizophrenia Stimulus}

\section{Taylor Johnson}

5423 Ashley Way Ct Sugar Land, TX 77479

Cell: 713-516-2281

Please note: There is a gap in my resume because I was diagnosed with schizophrenia and could not work due to medical treatment.

\section{PROFESSIONAL EXPERIENCE:}

Jack's Carpet Sugar Land, TX

March 2015 - April 2017

Sales Consultant

- Responsibilities included selling flooring and customer relations, ordering product, scheduling installation jobs and coordinating work crews, product research, and distributor interaction

American Direct Inc Austin, TX

January 2014 - October 2014

Sales/Warehouse Manager

- Responsibilities included pitching sales presentations, closing deals, store opening and closing duties, payroll, supervising a 20 person phone room, customer relations, employee scheduling, organizing sales representative rotation, gross profit reports, reporting to upper management, among others.

- Promoted from sales associate in April 2007

Old San Francisco Steakhouse Houston, TX

March 2008 - May 2011

Floor Manager

- Responsibilities included customer relations, daily operations, daily set up and break down of the restaurant, serving tables and bartending when needed, supervision and support of the wait staff, taking in money and reports from wait staff at the end of shifts, among others.

Denny's Restaurant Missouri City, TX

June 2003 - July 2007

Shift Manager, Server

- Responsibilities included shift scheduling, inventory, serving tables, working the cash register, among others.

- I was promoted from server and given a raise during my employment here

EDUCATION:

University of Houston Houston, TX

Bachelor of Science in Psychology, Business Administration minor

Clements High School Sugar Land, TX

HONORS:

- I am a member of Phi Theta Kappa (national honors society).

- University of Houston Dean's List (Spring 2016, Fall 2016, Spring 2017)

\section{REFERENCES:}

- Robin Smith, Supervisor, (646) 504-1651

- Additional references available upon request 